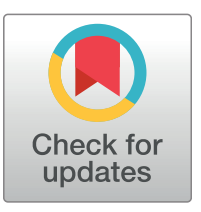

\section{G OPEn ACCESS}

Citation: Capitao C, Tanasa S, Fulnecek J, Raxwal VK, Akimcheva S, Bulankova P, et al. (2021) A CENH3 mutation promotes meiotic exit and restores fertility in SMG7-deficient Arabidopsis. PLoS Genet 17(9): e1009779. https://doi.org/ 10.1371/journal.pgen.1009779

Editor: Gregory P. Copenhaver, The University of North Carolina at Chapel Hill, UNITED STATES

Received: April 12, 2021

Accepted: August 16, 2021

Published: September 30, 2021

Peer Review History: PLOS recognizes the benefits of transparency in the peer review process; therefore, we enable the publication of all of the content of peer review and author responses alongside final, published articles. The editorial history of this article is available here: https://doi.org/10.1371/journal.pgen.1009779

Copyright: @ 2021 Capitao et al. This is an open access article distributed under the terms of the Creative Commons Attribution License, which permits unrestricted use, distribution, and reproduction in any medium, provided the original author and source are credited.

Data Availability Statement: All relevant data are within the manuscript and its Supporting information files.

RESEARCH ARTICLE

\title{
A CENH3 mutation promotes meiotic exit and restores fertility in SMG7-deficient Arabidopsis
}

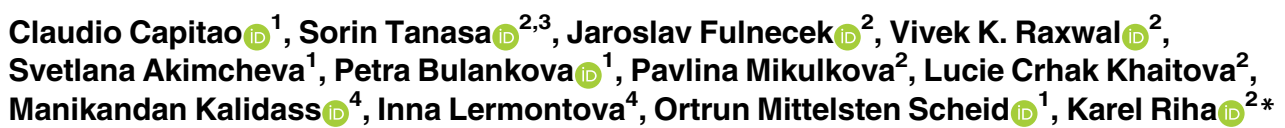

1 Gregor Mendel Institute, Austrian Academy of Sciences, Vienna, Austria, 2 Central European Institute of Technology (CEITEC), Masaryk University, Brno, Czech Republic, 3 National Centre for Biomolecular Research, Faculty of Science, Masaryk University, Brno, Czech Republic, 4 Leibniz Institute of Plant Genetics and Crop Plant Research, Gatersleben, Germany

* karel.riha@ceitec.muni.cz

\section{Abstract}

Meiosis in angiosperm plants is followed by mitotic divisions to form multicellular haploid gametophytes. Termination of meiosis and transition to gametophytic development is, in Arabidopsis, governed by a dedicated mechanism that involves SMG7 and TDM1 proteins. Mutants carrying the smg7-6 allele are semi-fertile due to reduced pollen production. We found that instead of forming tetrads, smg7-6 pollen mother cells undergo multiple rounds of chromosome condensation and spindle assembly at the end of meiosis, resembling aberrant attempts to undergo additional meiotic divisions. A suppressor screen uncovered a mutation in centromeric histone $\mathrm{H} 3(\mathrm{CENH} 3)$ that increased fertility and promoted meiotic exit in smg7-6 plants. The mutation led to inefficient splicing of the CENH3 mRNA and a substantial decrease of $\mathrm{CENH} 3$, resulting in smaller centromeres. The reduced level of $\mathrm{CENH} 3$ delayed formation of the mitotic spindle but did not have an apparent effect on plant growth and development. We suggest that impaired spindle re-assembly at the end of meiosis limits aberrant divisions in smg7-6 plants and promotes formation of tetrads and viable pollen. Furthermore, the mutant with reduced level of $\mathrm{CENH} 3$ was very inefficient haploid inducer indicating that differences in centromere size is not the key determinant of centromeremediated genome elimination.

\section{Author summary}

Meiosis is a reductional cell division that halves number of chromosomes during two successive rounds of chromosome segregation without intervening DNA replication. Such mode of chromosome segregation requires extensive reprogramming of the cell division machinery at the entry to meiosis, and inactivation of the meiotic program upon the formation of haploid spores. Here we showed that Arabidopsis partially deficient in the RNA decay factor SMG7 fail to exit meiosis and continue with attempts to undergo additional cycles of post-meiotic chromosome segregations without genome replication. This results 
Funding: This work was supported from the European Regional Development Fund-Project 'REMAP' (No. CZ.02.1.01/0.0/0.0/15_003/0000479 to K.R.), Doctoral School "Chromosome Dynamics" of the Austrian Science Fund (FWF W1238 to K.R. and O.M.S.), Vienna Science and Technology Fund (WWTF LS13-057 to 0.M.S.) and the German Federal Ministry of Education and Research (Plant 2030, Project 031B0192NN, HaploTools, to I.L.). The core facility CELLIM of CEITEC is supported by MEYS CR (LM2018129 Czech-Biolmaging). The funders had no role in study design, data collection and analysis, decision to publish, or preparation of the manuscript. Funders web sites: MEYS: https://www.msmt.cz/ Austrian Science Fund: https://www.fwf.ac.at/ Vienna Science and Technology Fund: https://www. wwtf.at/ German Federal Ministry of Education and Research https://www.bmbf.de/.

Competing interests: The authors have declared that no competing interests exist. in a reduced number of viable pollen and diminished fertility. To find genes involved in meiotic exit, we performed a suppressor screen for the SMG7-deicient plants that re-gain fertility. We found that reducing the amount of centromeric histone partially restores pollen formation and fertility in $s m g 7$ mutants. This is likely due to inefficient formation of centromere-microtubule interactions that impairs spindle reassembly and re-entry into aberrant rounds of post-meiotic chromosome segregation.

\section{Introduction}

A sexual life cycle consisting of alternating haploid and diploid life forms is the defining feature of eukaryotes. Entry into the haploid phase requires meiosis, a reductional cell division that forms four haploid cells from a single diploid precursor. It involves segregation of homologous chromosomes in the first meiotic division that is followed, without intervening DNA replication, by segregation of sister chromatids in the second meiotic division. In contrast to the mitotic cell division machinery, meiosis requires mechanisms for tethering homologous chromosomes via recombination in prophase I, sister kinetochore monoorientation and protection of centromeric cohesion in metaphase-anaphase I, and inhibition of DNA replication in interkinesis [1,2]. While the sequence of meiotic events is evolutionally highly conserved, regulation of meiosis and its position in the context of the life cycle differ across diverse phylogenetic units [3,4].

Meiosis in angiosperm plants occurs in megaspore and pollen mother cells located in pistils and anthers, respectively, and leads to the formation of haploid spores. Rudimentary multicellular gametophytes carrying male and female gametes are formed by subsequent mitotic divisions. A number of genes involved in induction, progression, and termination of the meiotic program have been identified in plants. Genes required for meiotic fate acquisition and progression through early meiotic events include the transcription factor SPOROCYTELESS, RNA binding protein MEL2, AMEIOTIC1/SWITCH1, and RETINOBLASTOMA RELATED1 [5-9]. Redox status and small-RNA-mediated gene silencing have also been implicated in establishing meiotic cell fate [10-12]. Entry into meiosis is further accompanied by the induction of genes required for core meiotic functions $[13,14]$.

Progression through the meiotic cell cycle is driven by cyclin dependent kinases (CDKs), in Arabidopsis mainly by CDKA;1, the key CDK that is also required for mitosis [15]. CDKA;1 plays a role in regulating meiotic spindle organization, cytokinesis, as well as recombination and chromosome pairing [16-18]. CDKA;1 activity is modulated by several mechanisms to implement the meiotic program. CDK substrate specificity is determined through association with different cyclins. Several A- and B- type cyclins are expressed in Arabidopsis pollen mother cells (PMCs) [19] and CDKA;1 was found to interact with at least three of them. SOLO DANCERS (SDS) is a meiosis-specific cyclin that mediates phosphorylation of the chromosome axis assembly factor ASYNAPTIC 1 (ASY1) and is essential for homologous recombination and pairing $[16,20]$. A-type cyclin TARDY ASYNCHRONOUS MEIOSIS (TAM) and CYCB3;1 have been implicated in organization of the meiotic spindle and regulation of cell wall formation [16,19,21,22]. An important aspect of meiosis is the absence of S-phase in interkinesis between meiosis I and II. In yeasts and mammals, this is achieved via partial inhibition of the anaphase promoting complex (APC/C) after anaphase I, which results in residual CDK activity in interkinesis to prevent DNA replication. A similar mechanism was also suggested in Arabidopsis, where inactivation of the APC/C inhibitor OMISSION OF SECOND DIVISION 1 (OSD1) leads to premature meiotic exit after meiosis I [23,24]. 
Two genes have been implicated in terminating the meiotic program and enabling the transition to gametophytic development in Arabidopsis. THREE DIVISION MUTANT1 (TDM1)/ MS5/POLLENLESS3 is a plant-specific gene that is exclusively expressed in meiocytes, and loss of its function results in male sterility [25-28]. Mutant PMCs fail to exit meiosis and the chromosomes of the haploid nuclei re-condense, nucleate four spindles, and attempt to undergo a third division $[25,29]$. Another gene required to terminate meiosis is SUPPRESSOR WITH MORPHOGENETIC EFFECTS ON GENITALIA7 (SMG7), an evolutionary conserved protein involved in nonsense-mediated RNA decay (NMD). Arabidopsis smg7-null mutants are NMD-deficient, exhibit stunted growth due to an upregulated immune response, and are infertile $[30,31]$. The infertility is caused by meiotic arrest in anaphase II and inability to exit meiosis. Analysis of plants with a hypomorphic smg7-6 allele that contains a T-DNA insertion in the diverged C-terminal domain of the gene indicate that the meiotic function of SMG7 is not connected to its role in NMD [32], but the mechanism of its action in meiosis remains unknown.

We reasoned that mutations that restore fertility and increase pollen count in $s m g 7-6$ mutants might help identify genes that affect meiotic exit in Arabidopsis and therefore performed a genetic suppressor screen in this background. We identified two suppressor lines with a mutation in the $\mathrm{CENH} 3$ gene, which encodes the centromeric variant of histone $\mathrm{H} 3$. This mutation does not alter the amino acid sequence of the protein but leads to inefficient splicing of CENH3 mRNA and a substantial reduction of CENH3 protein levels. We describe the consequences of decreased CENH3 for meiosis, mitosis, and centromere-mediated induction of haploid plants.

\section{Results}

\section{Meiosis in smg7-6 PMCs is followed by multiple rounds of spindle reassembly prior to polyad formation}

The multiple functions of Arabidopsis SMG7 were described in our previous studies of an allelic series of T-DNA insertion mutants in this gene [32]. The $s m g 7-1$ and $s m g 7-3$ alleles, disrupted in the conserved central domain, are NMD-deficient and exhibit retarded growth and defects in leaf development and shoot branching (S1 Fig). In addition, smg7-1 and smg7-3 mutants are completely sterile (Fig 1A)[30]. In contrast, smg7-6 mutants, which contain a T-DNA insertion downstream of the conserved central domain, grow normally and are only mildly deficient in NMD [31](S1 Fig). Nevertheless, fertility is strongly reduced in early flowers of $s m g 7-6$ plants, but, in contrast to $s m g 7-1$ and $s m g 7-3$, some seeds are produced from late flowers. Anthers of these flowers have approximately 10-times less viable pollen than wild type (Fig 1A). We noticed that seed production is approximately halved upon pollination of $s m g 7-6$ mutants with wild type pollen indicating that the female gametophyte is also affected (S2 Fig). Because the $s m g 7-6$ phenotype differed from the one detected in $s m g 7-1$, we transformed the mutant with the wild-type SMG7 gene construct. This complementation restored pollen production and confirmed that the reduced fertility is indeed caused by the smg7-6 allele (S3 Fig).

Previous cytogenetic analysis performed on dissected smg7-6 meiocytes showed PMCs seemingly arrested in anaphase II, as well as meiocytes that reached telophase II [32]. This observation can be interpreted as a reduced penetrance of the $s m g 7$-null phenotype in mutants with this allele, allowing occasional continuation into normal pollen development. If this were the case, one anther should contain a mixture of aberrant and normal meiocytes. To test this, we performed cytogenetic analysis of meiocytes in entire anthers. In contrast to our prediction, we observed anthers in which all meiocytes resembled aberrant anaphase II, as well as anthers with all meiocytes in telophase II (Fig 1B). This suggests that all meiocytes in smg7-6 plants are 

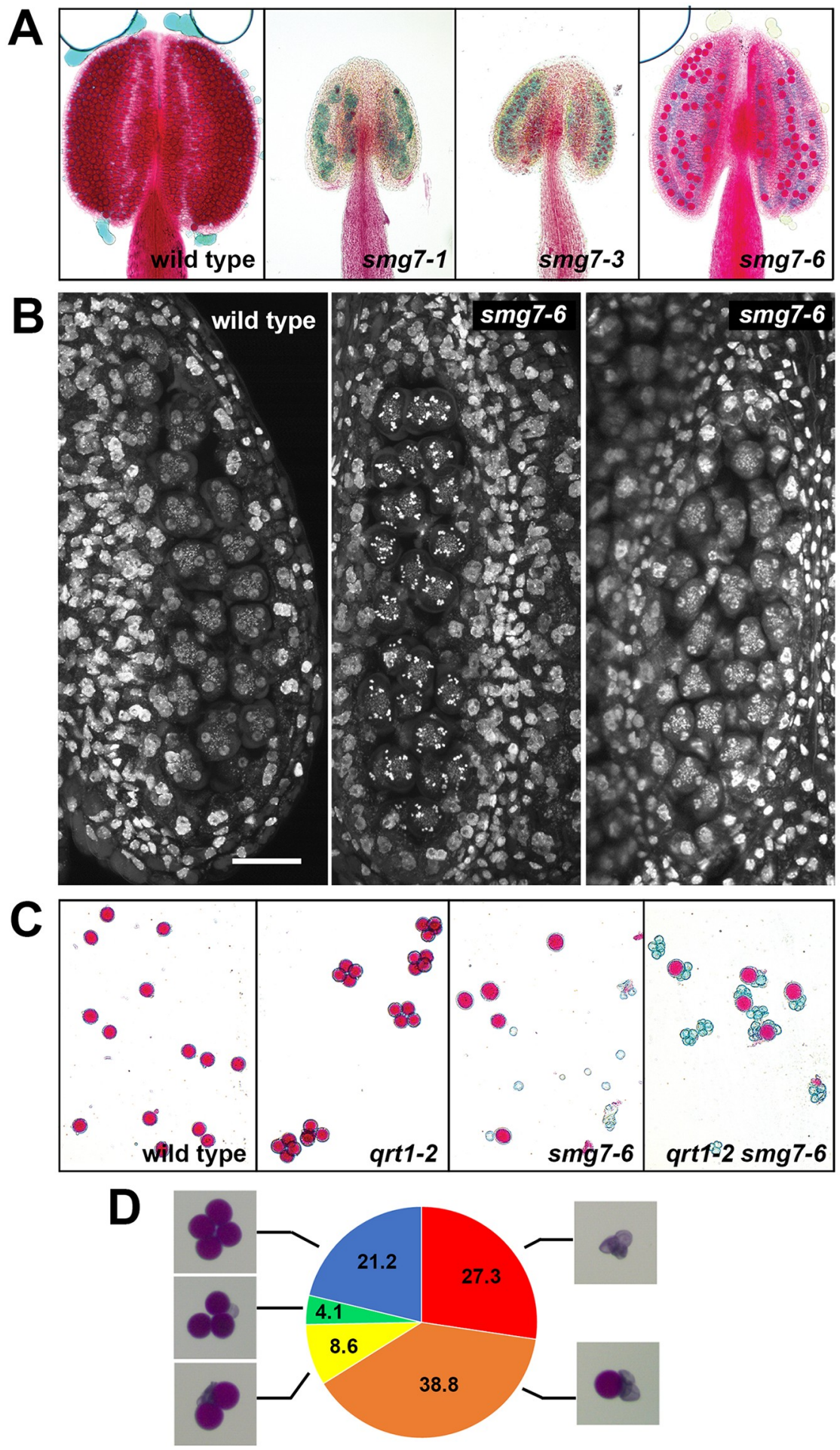

Fig 1. Aborted pollen development in smg7-6 mutants. (A) Anthers of indicated mutants after Alexander staining. Viable pollen stain red. (B) Anther loculi in telophase II (Col-0, smg7-6 left panel) and assumed aberrant anaphase II (smg7-6, middle panel) stained with DAPI. Scale bar corresponds to $20 \mu \mathrm{m}$. (C) Alexander staining of pollen produced by the indicated mutants. The qrt1-2 mutation causes pollen from one tetrad to remain together. (D) Percentage of tetrads with one, two, three, four or no viable pollen. 245 tetrads from qrt1-2 smg7-6 plants were counted.

https://doi.org/10.1371/journal.pgen.1009779.g001 
able to reach telophase II and that the residual fertility cannot be attributed to the reduced penetrance of the phenotype observed in smg7-1 mutant. To analyze pollen derived from the same meiocyte, we took advantage of the Arabidopsis qrt1 mutant that is deficient in post-meiotic pollen separation, resulting in pollen tetrads that remain tethered together. Analysis of qrt1-2 smg7-6 double mutants showed that tetrads mainly consisted of one viable and three aborted pollen (Fig 1C and 1D), eliminating the possibility that viable pollen originated from a bypass of anaphase II arrest and continuation of normal pollen development for all four products.

We next performed immunocytogenetic analysis of dissected $s m g 7-6$ meiocytes stained with an $\alpha$-tubulin antibody. We detected meiocytes containing four separate spindles, each attached to approximately five chromatids (Fig $2 \mathrm{~A}$ ). This phenotype resembles $t d m 1$ mutants, where haploid nuclei re-enter a third division without preceding DNA replication (Fig 2A). Nevertheless, $t d m 1$ and $s m g 7-6$ mutations have slightly different phenotypes. In contrast to smg7-6 plants, $t d m 1$ mutants are infertile and do not form any pollen (S4A Fig). We have also noticed that chromatids in $t d m 1$ mutants condense only partially during the aberrant postmeiotic division, while they fully condense in $s m g 7-6$ plants (Fig 2B). $t d m 1$ is epistatic to $s m g 7-$ 6 as $t d m 1 s m g 7-6$ double mutants are infertile and exhibit partially condensed chromosomes during the third meiotic division (S4B Fig).

To gain more insights into meiotic progression in $s m g 7-6$ plants, we performed time-lapse analysis of PMCs using fluorescently labelled tubulin [22,33]. In wild type, microtubules undergo two rounds of spindle formation in meiosis I and meiosis II, separated by spindle disassembly in interkinesis (Fig 3A and 3B; S1 Movie). By tracking spindle formation, we determined the duration of metaphase I to telophase II, interkinesis, and metaphase II to telophase II in wild type to be 46, 38, and $39 \mathrm{~min}$, respectively, with cytokinesis ensuing $203 \mathrm{~min}$ after meiosis II spindle disassembly (average values from 5 meiocytes). PMCs in smg7-6 mutants underwent up to four additional cycles of spindle assembly and disassembly beyond meiosis II (Fig 3A and 3C; S2 and S3 Movies). We also noticed that meiosis I and II in smg7-6 plants were extended to an average of 66 and $67 \mathrm{~min}$, respectively ( $\mathrm{n}=5$ meiocytes; Fig 3B). While the interkinesis II that preceded meiosis III was relatively brief ( $32 \mathrm{~min}$ ), interkinesis in subsequent cycles were substantially longer (Fig 3B).

These observations indicate that $s m g 7-6$ plants are unable to complete meiosis by regular cytokinesis. Instead, after meiosis II, smg7-6 PMCs undergo several cycles of spindle assembly/ disassembly and chromatin condensation/decondensation, leading to an unequal distribution of chromatin and formation of polyads that only exceptionally form functional haploid microspores and pollen. We did not detect any aneuploids among 19 cytologically scored progeny of smg7-6 self-pollinated plants indicating that the majority of viable pollen do not contain supernumerary chromosomes. This indicates that the viable pollen are not derived from stochastic clustering of chromosomes, but rather represent events where the original set of chromosomes remained associated throughout the cycles of chromatin condensation and decondensation.

\section{Suppressor screening results in mutations that recover fertility of $s m g$ 7-6 plants}

SMG7 and TDM1 are important elements of a regulatory network that governs meiotic exit in Arabidopsis [29]. To uncover additional genes and molecular processes required for transition from meiosis to pollen differentiation, we performed a forward genetic screen for mutants that restore the fertility of $s m g 7-6$ plants. The screen is based on a characteristic feature of $s m g 7-6$ mutants: the first 20-25 flowers on the main inflorescence bolt are infertile and only later flowers give rise to seeds (Fig 4A and 4B). Interestingly, pollen production and ability to form seeds are reduced to a similar extend in all flowers, indicating that increased fertility in late 


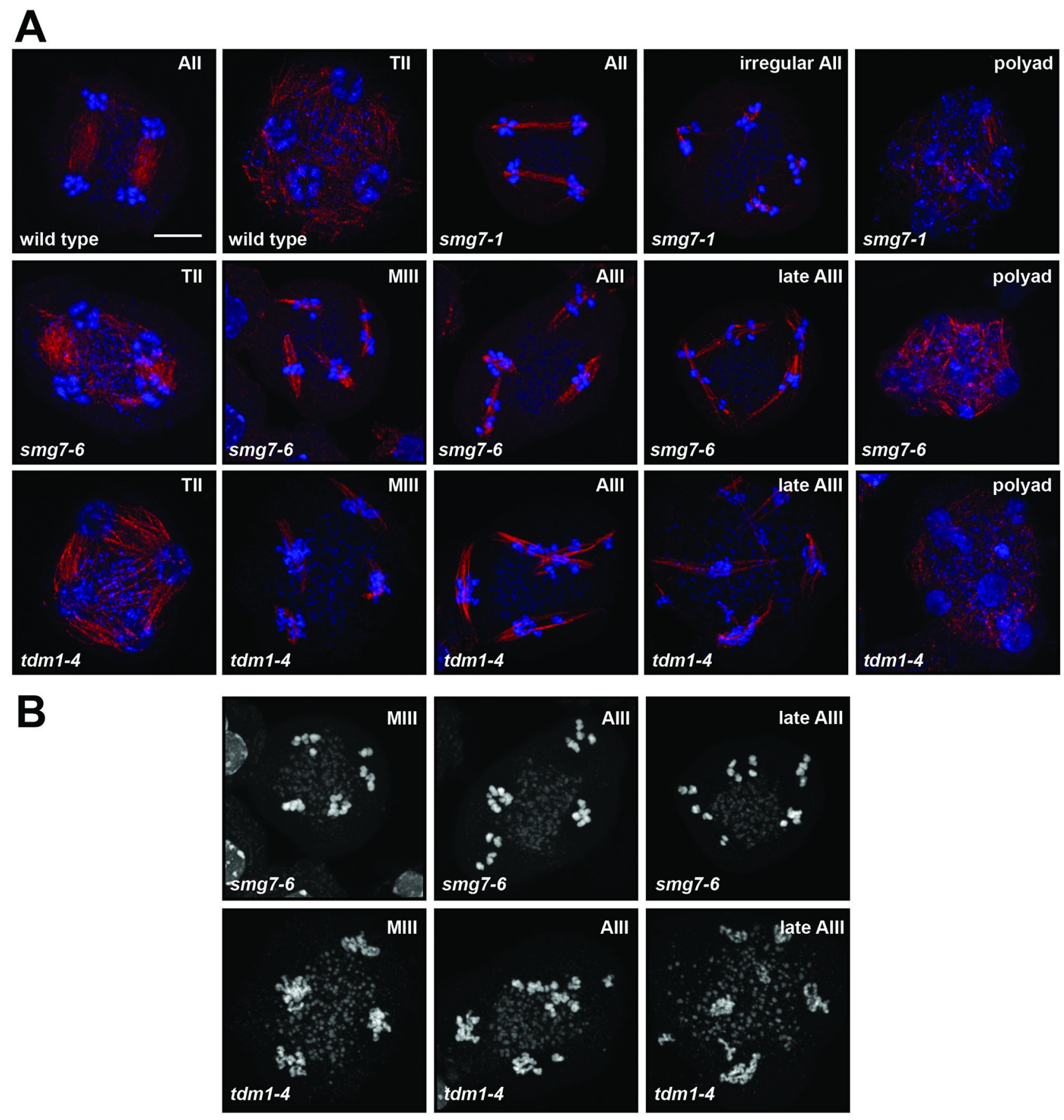

Fig 2. Meiosis in $\boldsymbol{s} m \boldsymbol{g} \mathbf{7}$ and $\boldsymbol{t} \boldsymbol{d} \boldsymbol{m} \mathbf{1}$ mutants. (A) Immunodetection of spindles using anti- $\alpha$-tubulin antibody (red) in pollen mother cells. DNA is counterstained by DAPI (blue). AII—anaphase II, TII—-telophase II, MIII-metaphase III, AIII-anaphase III. (B) Structure of chromosomes counterstained by DAPI in the third meiotic division.

https://doi.org/10.1371/journal.pgen.1009779.g002

flowers is not caused by changes in the meiotic program during plant aging, but rather by unknown physiological factors that affect pollination or fertilization (S2 Fig and Fig 4C and 4D). In the screen, we scored plants from the M2 population of ethyl-methanesulfonate (EMS)-mutagenized smg7-6 plants and selected suppressor lines that produced seeds from the 


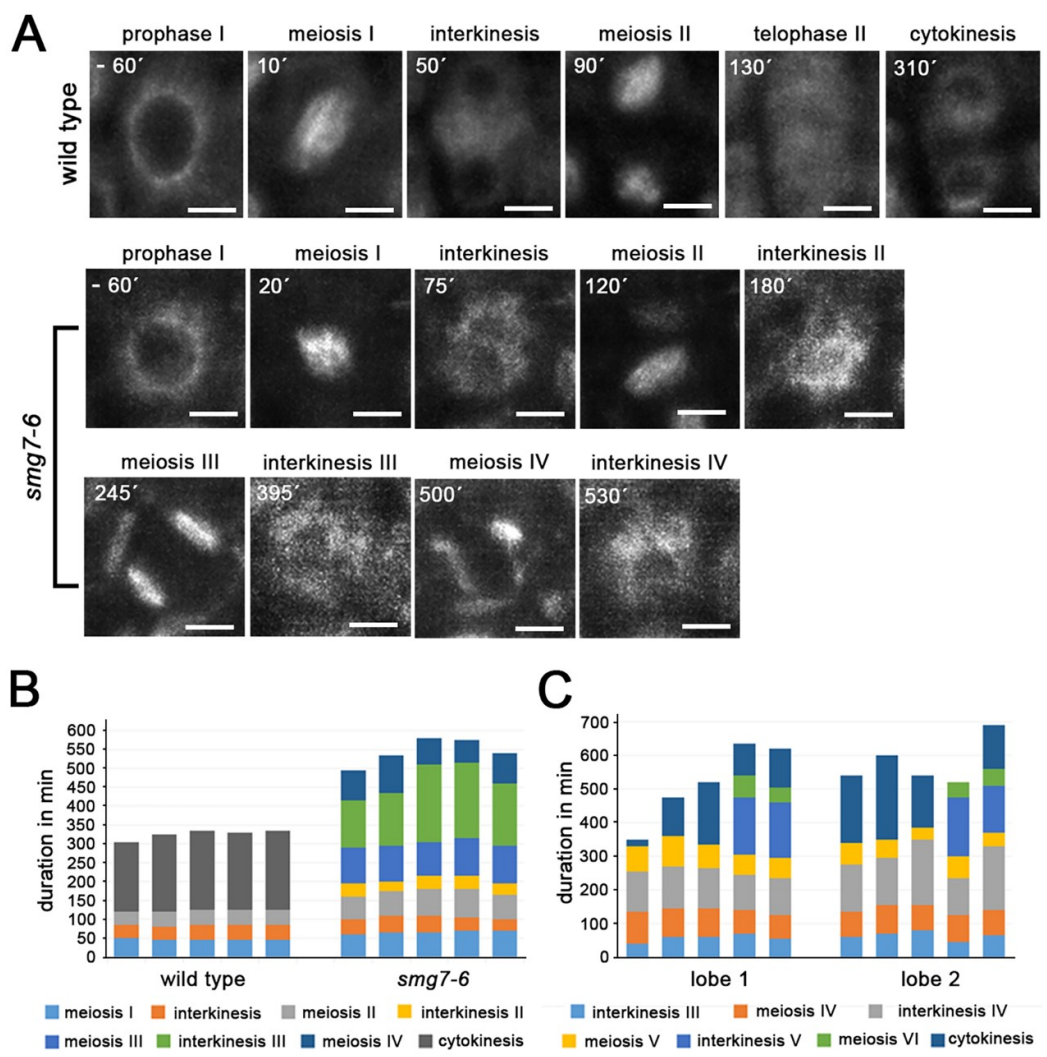

Fig 3. Live imaging of meiotic progression in smg7-6 PMCs. (A) Time-lapse series of PMCs containing microtubules labeled with the $\mathrm{p} R P S 5 A:: T a g R F P: T U B 4$ construct. Timepoints relate to nuclear envelope breakdown at the end of prophase I. Scale bars correspond to $5 \mu \mathrm{m}$. (B) Duration of indicated meiotic stages inferred from spindle dynamics in time-lapse movies of pRPS5A::TagRFP:TUB4. Five individual PMCs from each wild type and smg7-6 plants are shown. (C) Duration of postmeiotic cycles of spindle assembly and disassembly in individual PMCs from two separate anther lobes of $s m g 7-6$ mutants.

https://doi.org/10.1371/journal.pgen.1009779.g003

first 20 flowers on the main inflorescence bolt. Two suppressor lines, EMS30 and EMS155, are characterized in detail in this study.

Both lines produce seeds and substantially longer siliques from early flowers, although the siliques are still shorter than in wild type (Fig 4A and 4B). They also generate about 250 viable pollen per anther, which is six times more than smg7-6 plants and approximately half of that in wild type (Fig 4C and 4D). While cytogenetic analysis revealed some meiocytes still undergoing a third meiotic division (Fig 5A), their abundance substantially decreased in comparison with smg7-6 mutants (Fig 5B). Whole anther staining showed a number of meiocytes forming tetrads, while only a relatively small fraction exhibited the aberrant post-meiotic divisions (Fig 5C). Therefore, the aberrant exit from meiosis in smg7-6 PMCs is at least partially suppressed in the double mutants, resulting in a relatively high level of correct tetrad formation and improved seed set.

\section{Restored fertility is caused by mutation in CENH3}

To identify the mutations responsible for the restored fertility, we created mapping populations by backcrossing EMS30 and EMS155 lines to the parental smg7-6. The restored fertility phenotype segregated as a recessive trait. EMS-induced de novo mutations were identified by comparing genome sequencing data from pools of fertile B2 plants with the parental smg7-6 


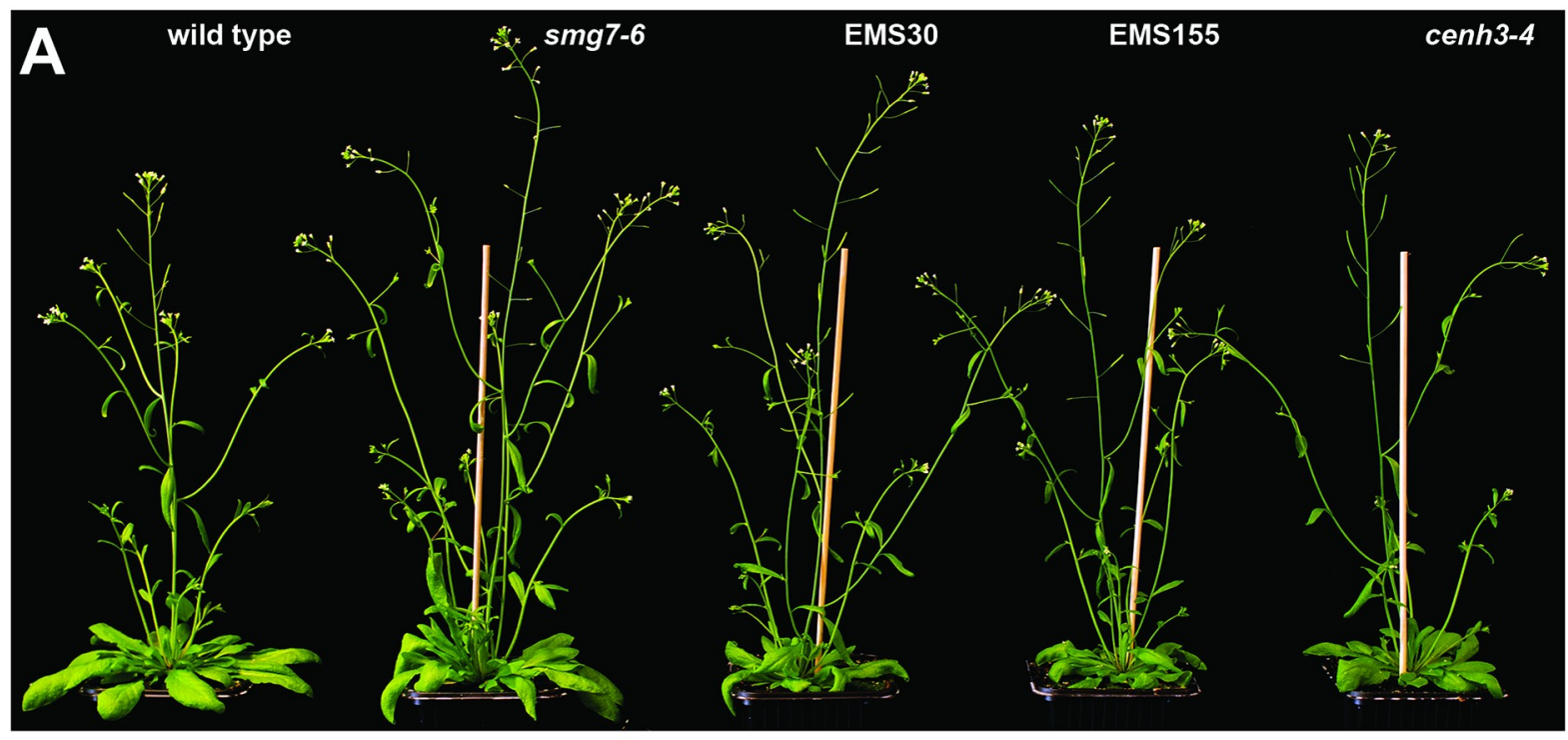

B

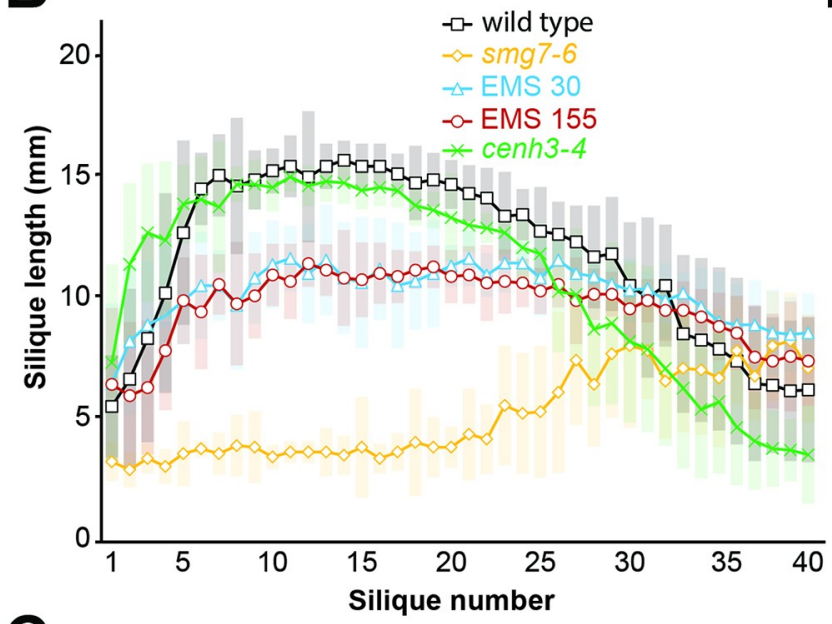

C

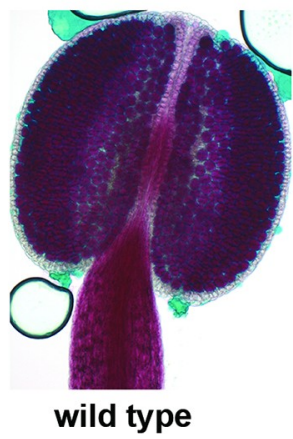

D
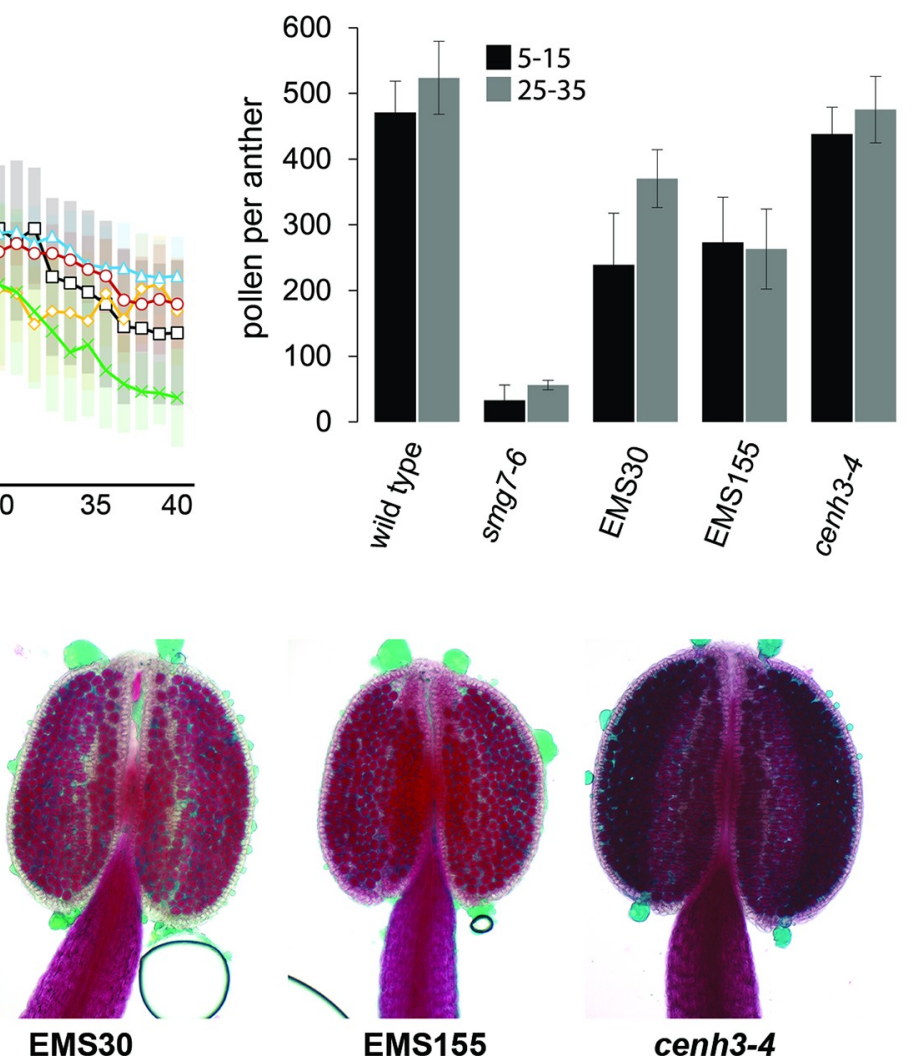

Fig 4. Characterization of the EMS30 and EMS155 suppressor lines. (A) Five week-old plants of indicated genotypes. (B) Analysis of silique length along the main inflorescence bolt in wild type $(\mathrm{n}=16), \operatorname{smg7-6}(\mathrm{n}=15)$, EMS30 $(\mathrm{n}=16)$, EMS155 $(\mathrm{n}=15)$ and cenh3-4 $(\mathrm{n}=16)$ plants. Position 1 corresponds to the oldest and position 40 to the youngest silique scored on the main bolt. Error bars represent standard deviations. (C) Anthers of indicated lines after Alexander staining. (D) Number of viable pollen per anther from flowers at positions 5-15 and 25-35 along the main inflorescence bolt. Error bars represent standard deviations $(n=9)$.

https://doi.org/10.1371/journal.pgen.1009779.g004 


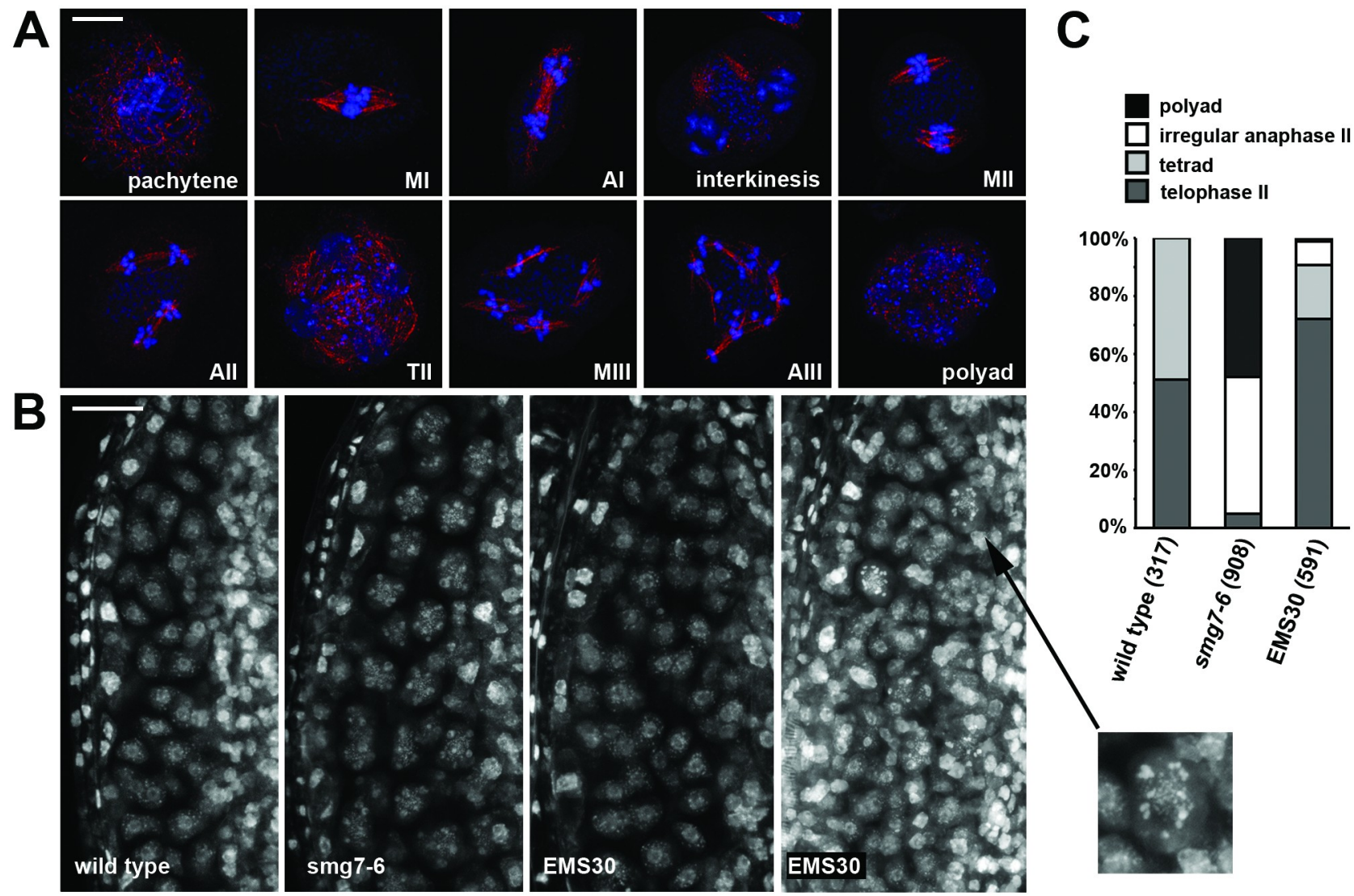

Fig 5. Meiotic progression in the EMS30 line. (A) Immunocytological analysis of EMS30 PMCs with spindles visualized with anti- $\alpha$-tubulin antibody (red). DNA is counterstained with DAPI (blue). MI, MII, MIII - metaphase I, II, III; AI, AII, AIII—anaphase I,II, III; TII-telophase II. Scale bar represents $5 \mu \mathrm{m}$. (B) Anther loculi stained with DAPI. Wild type and $s m g 7-6$ loculi contain tetrads and polyads, respectively. EMS30 plants contain tetrads (middle panel) and a mixture of polyads, tetrads, and AIII in their loculi (right panel). The inset shows a detail of a PMC in the MIII/AIII stage. Scale bar represents $20 \mu \mathrm{m}$. (C) Quantification of PMCs in late stages of meiosis. Number of PMCs analyzed for each genotype is indicated in parentheses.

https://doi.org/10.1371/journal.pgen.1009779.g005

genome using the ArtMAP mapping algorithm [34]. Although EMS30 and EMS155 contained different de novo mutations distributed throughout their genomes, they shared one identical polymorphism in the CENH3 gene at the end of the left arm of chromosome 1 (S5 Fig). The mutation was present with $100 \%$ frequency in the pools with DNA from fertile plants in the B2 populations derived from EMS30 and EMS155 lines. In both cases, the mutation represents a $\mathrm{G}$ to $\mathrm{A}$ transition in the splicing donor site of the $3^{\text {rd }}$ exon of the CENH3 gene (Fig 6A). It is a silent mutation that does not alter amino acid sequence. Since this mutation was uncovered independently in two suppressor lines that do not share any other de novo polymorphism, we consider this mutation to be responsible for the restored fertility of $s m g 7-6$ and refer to it as the cenh3-4 allele.

By backcrossing the mutant suppressor line with wild type, selfing the progeny, and genotyping in the F2, we also generated a line which carries the cenh3-4 allele independent from the smg7-6 mutation. As a single or double mutant, the cenh3-4 mutation causes inefficient splicing and retention of the third intron, which results in an approximately 10 -fold reduction of fully spliced $C E N H 3$ mRNA (Fig 6B). We used two combinations of primers matching either wild type (CENH3-G) or mutant (CENH3-A) cDNA to ascertain that the observed reduction 

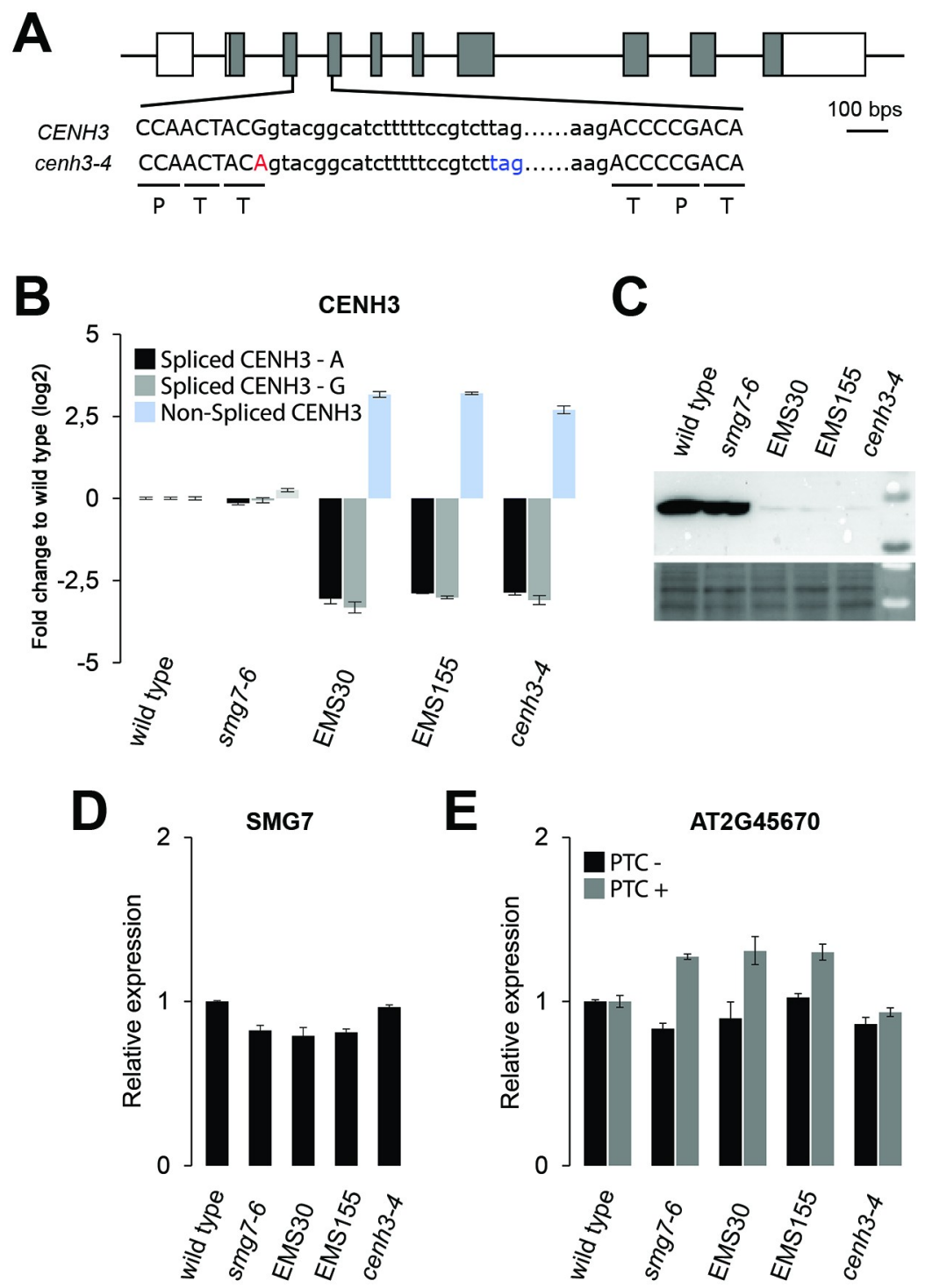

Fig 6. Molecular characterization of the cenh3-4 allele. (A) Diagram of the CENH3 gene with exons marked as boxes. DNA sequence surrounding the intron 3 is shown; capital letters depict exons. Amino acids encoded by canonically spliced mRNA are indicated. The cenh3-4 mutation at the splice donor site of exon 3 is indicated in red, stop codon in the intron of unspliced mRNA in blue. (B) Relative abundance of spliced and unspliced CENH3 mRNA determined by quantitative RT-PCR. Two sets of primers were designed for fully spliced mRNA matching either wild type (CENH3-G) or cenh3-4 (CENH3-A) allele sequences. (C) Western blot detection of total CENH3 protein by antiCENH3 antibody. Protein loading is shown on a Ponceau-S stained membrane (bottom panel). (D) Abundance of SMG7 mRNA relative to wild type determined by qRT-PCR. (E) NMD efficiency assessed by qRT-PCR analysis of alternatively spliced variants of the AT2G45670 gene with or without a premature termination codon (PTC) relative to wild type. Error bars in (B), (D) ad (E) represent standard deviations from 3 biological replicas.

https://doi.org/10.1371/journal.pgen.1009779.g006

is due to lower level of spliced CENH3 mRNA and not because of inefficient RT-PCR amplification (Fig 6B). Since the mis-spliced mRNA encodes a short open reading frame comprising only the first 32 amino acids of CENH3 (Fig 6A), cenh3-4 plants have a substantially decreased amount of CENH3 protein (Fig 6C). The cenh3-4 mutation does not affect expression of SMG7 mRNA or the efficiency of NMD, as the abundance of an endogenous transcript containing a premature termination codon is not altered (Fig 6D and 6E). 
CENH3 is a histone $\mathrm{H} 3$ variant that is specifically localized to centromeres. In Arabidopsis, CENH3 is loaded onto centromeres during G2 and remains there throughout the cell cycle [35]. To determine whether CENH3 is present on centromeric chromatin in cenh3-4 mutants, we performed immunolocalization using a CENH3 antibody. In wild type, we readily detected ten discrete dots in tapetum nuclei that likely correspond to ten centromeres, and approximately five pronounced dots in pachytene meiocytes that reflect synapsed centromeres of paired homologous chromosomes (Fig 7A and S6 Fig). In contrast, no signals were detected when we used the same imaging conditions in cenh3-4 mutants (S6 Fig). Substantially increasing the exposure time revealed weak fluorescence at DAPI-dense regions, indicating limiting amounts of CENH3 at the centromeres (Fig 7A). A substantial reduction of the CENH3 was also observed on centromeres in root and leaf nuclei of cenh3-4 mutants (S7 Fig). This was further validated by chromatin immunoprecipitation in seedlings that showed association of CENH3 with the Arabidopsis centromeric satellite repeat CEN180 in cenh3-4 plants, albeit at a lower level compared to wild type (Fig 7B and 7C). Thus, the cenh3-4 mutation substantially reduces the amount of $\mathrm{CENH} 3$ in centromeric chromatin.

CENH3 forms a hub for binding kinetochore proteins during chromosome segregation. Therefore, we next performed immunolocalization in cenh3-4 nuclei for CENP-C and MIS12, key proteins of the inner kinetochore complex [36,37], and KNL2, a CENH3 assembly factor [38]. CENP-C, MIS12 and KNL2 signals in cenh3-4 root nuclei were substantially lower than in wild type (Fig 8), suggesting that the decreased amount of CENH3 in the mutant affects the kinetochore structure.

\section{cenh3-4 affects mitotic progression and chromosome segregation}

Considering the role of CENH3 in chromosome segregation not only during meiosis, but also during the mitotic cell cycle and progression through M-phase, it was striking that the somatic growth of cenh3-4 plants was hardly affected, despite a drastically reduced level of CENH3. Mutant plants are viable, fertile, and do not show any gross growth retardation (Fig 4A). More thorough examination revealed that the roots of plants carrying the cenh3-4 allele grow slower when cultivated on agar plates (Fig 9A and 9B), which is indicative of impaired cell division. To reveal whether mitosis is affected in cenh3-4 plants, we performed live imaging of mitotic progression in root cells expressing the HTA10:RFP chromatin marker [33]. We determined the duration of early mitosis from nuclear envelope breakdown (NEB) through prometaphase to the end of metaphase, and of anaphase from chromatid separation to their arrival at the final position within the dividing cell (Fig 9C). We noticed that the duration of prometaphase/ metaphase is approximately twice as long in cenh3-4 mutants as in wild type, whereas anaphase is unaffected (Fig 9D, S4 and S5 Movies, Table 1).

A prolonged prometaphase indicates problems with chromosome biorientation and the formation of a bipolar spindle. Therefore, we next examined whether mitosis in cenh3-4 mutants is sensitive to oryzalin, a dinitroaniline herbicide that disrupts polymerization of microtubules [39]. We found that treatment of roots with $1.5 \mu \mathrm{M}$ oryzalin has a relatively mild effect on mitotic progression in wild type, causing extension of the prometaphase from 10 to 14 min, which was followed by a normal anaphase (Fig 9D, Table 1, S6 Movie). However, the same concentration of oryzalin inhibited chromosome biorientation and formation of a stable metaphase plate in cenh3-4 mutants. All scored cells entering mitosis remained arrested in prometaphase and did not reach anaphase even after $1 \mathrm{hr}$ of recording (Table 1, S7 Movie). The increased sensitivity to a microtubule inhibitor indicates that association of kinetochores with microtubules is impaired in cenh3-4 plants. 


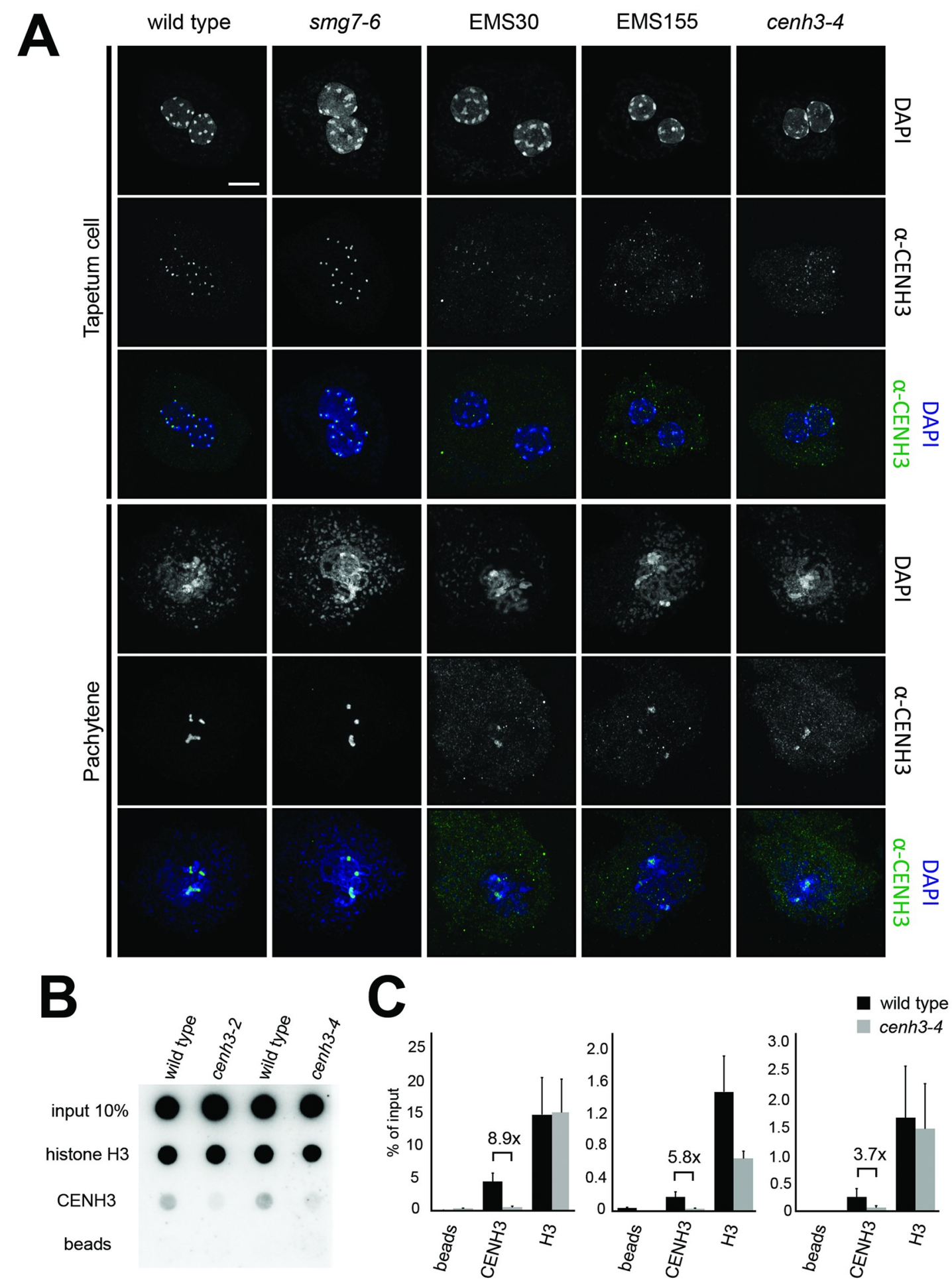

Fig 7. Effect of cenh3-4 mutation on the localization of CENH3 on Arabidopsis centromeres. (A) Immunodetection of CENH3 in PMCs and tapetum cells using $\alpha$-CENH3 antibody (green); DNA is counterstained with DAPI (blue). Longer exposure times for EMS30, EMS155, and cenh3-4 were applied to detect the signal. Scale bar corresponds to $5 \mu \mathrm{m}$. (B) Association of CENH3 with the CEN180 satellite repeat determined by chromatin immunoprecipitation with CENH3 antibody and dot blot hybridization. Antibody against histone H3 was used as a control. (C) Quantification of the CEN180 repeat in the ChIP experiments by qPCR. Error bars represent standard deviation of three technical replicates. Three independent experiments are presented. 

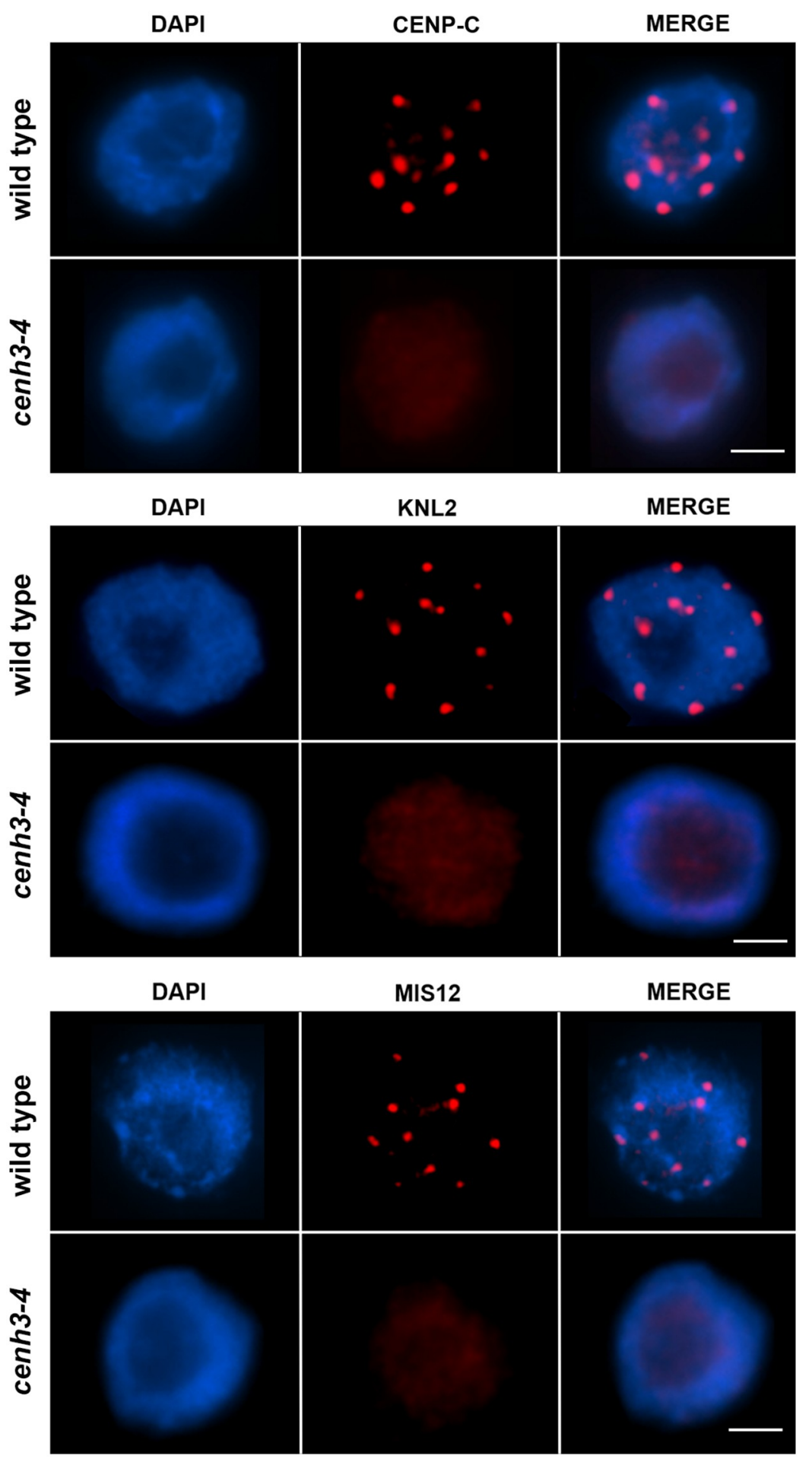

Fig 8. Immunodetection of CENP-C, KNL2 and MIS12 in root nuclei of cenh3-4 and wild type. DNA is counterstained with DAPI (blue). Longer exposure times for cenh3-4 were applied to detect a signal. Scale bar $=5 \mu \mathrm{m}$.

https://doi.org/10.1371/journal.pgen.1009779.g008 


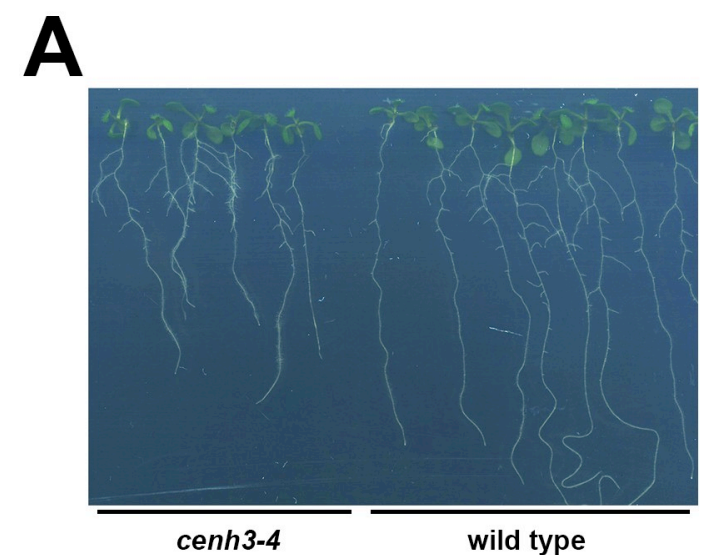

B
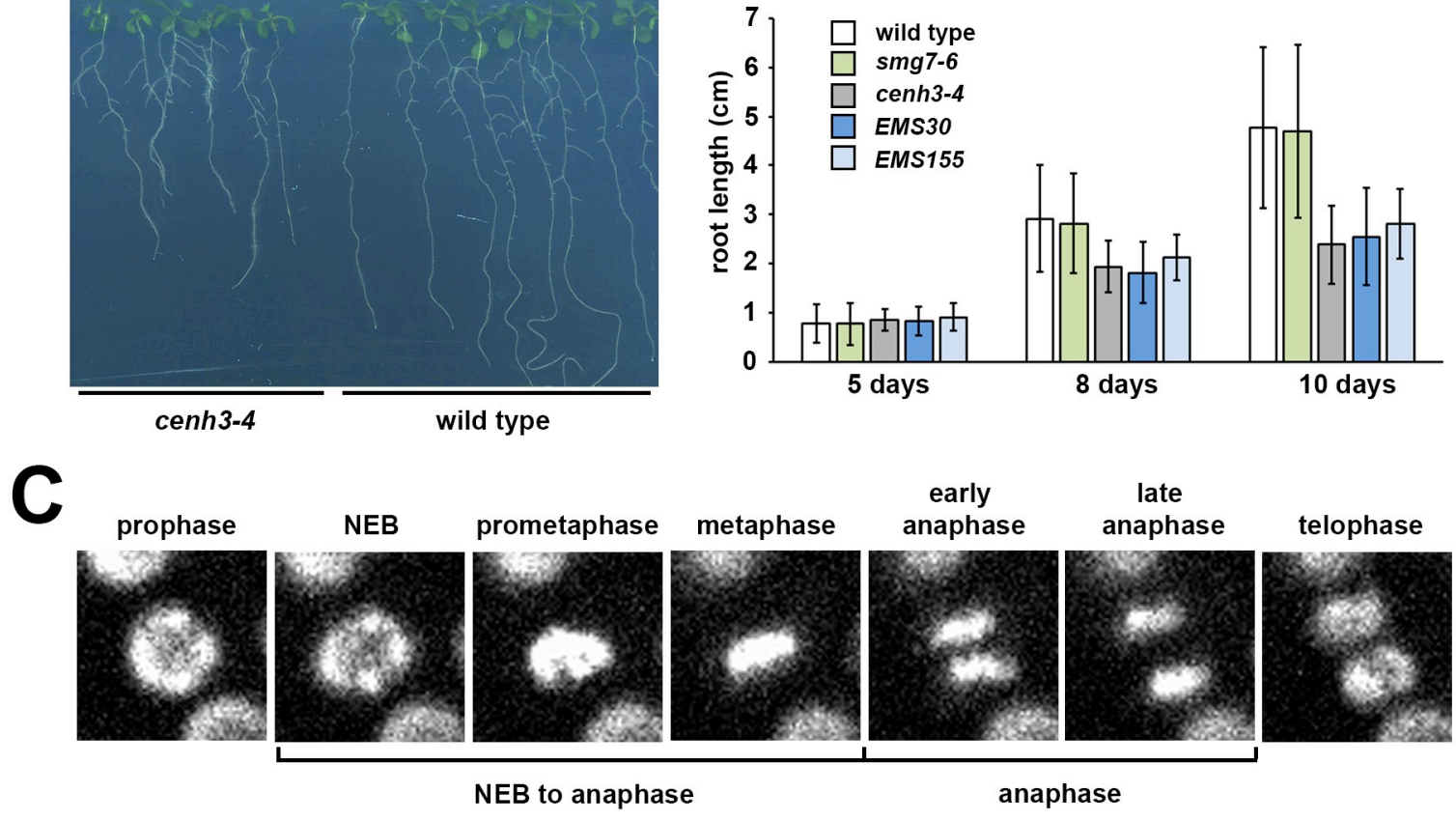

D
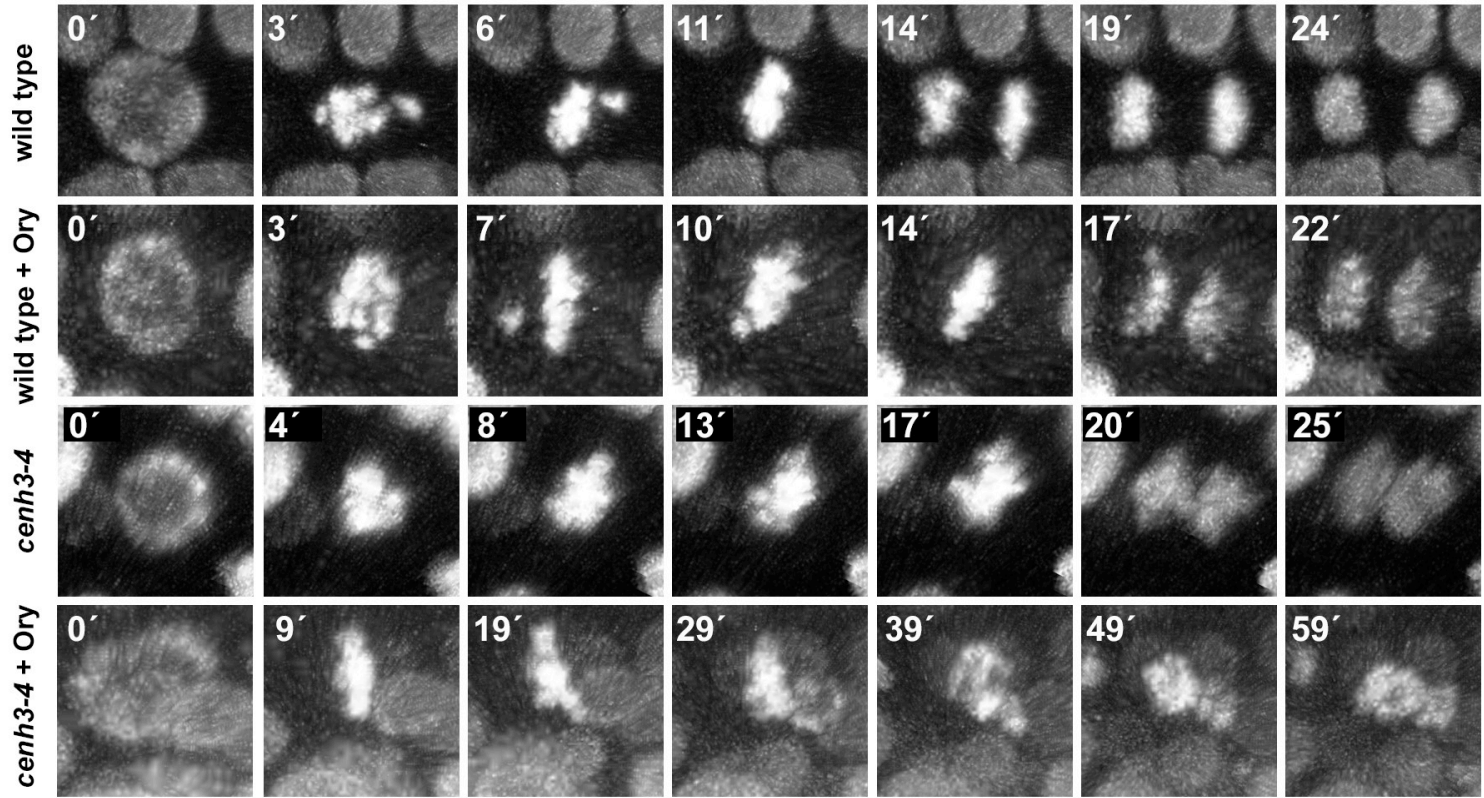

Fig 9. Mitotic defects in cenh3-4 mutants. (A) Seedlings grown on vertically oriented agar plates for $10 \mathrm{~d}$ after germination. (B) Dynamics of root growth on vertical agar plate. Error bars represent standard deviations ( $n=17$ to 39). (C) An example of mitotic progression in a root cell visualized by the HTA10:RFP marker. Classification of stages whose duration was quantified in Table 1 is indicated. (D) Time-lapse series of mitotic nuclei from wild type and cenh3-4 plants that were treated with $1.5 \mu \mathrm{M}$ oryzalin (Ory) during the experiment.

https://doi.org/10.1371/journal.pgen.1009779.g009 
Table 1. Duration of mitotic phases in root cells. NEB was defined as a time point when nuclei lost round shape (Fig 9C). None of the examined cells in cenh3-4 roots treated with oryzalin that entered the mitosis formed a metaphase plate $(\mathrm{n}=12)$.

\begin{tabular}{|c|c|c|c|c|c|}
\hline \multirow{4}{*}{ Wild type } & \multirow{3}{*}{$\begin{array}{l}\text { NEB to anaphase } \\
\text { Anaphase }\end{array}$} & \multicolumn{2}{|c|}{ No oryzalin } & \multicolumn{2}{|c|}{ Oryzalin $1.5 \mu \mathrm{M}$} \\
\hline & & $10.0 \pm 1.3$ & \multirow{2}{*}{$\mathrm{n}=9$} & $13.8 \pm 2.9$ & \multirow[t]{2}{*}{$\mathrm{n}=13$} \\
\hline & & $4.2 \pm 0.7$ & & $4.2 \pm 0.8$ & \\
\hline & No metaphase & n. a. & $\mathrm{n}=0$ & n. a. & $\mathrm{n}=1$ \\
\hline \multirow[t]{3}{*}{ cenh3-4 } & NEB to anaphase & $20.8 \pm 5.9$ & \multirow[t]{2}{*}{$\mathrm{n}=14$} & n. a. & \multirow[t]{2}{*}{$\mathrm{n}=0$} \\
\hline & Anaphase & $4.2 \pm 0.7$ & & n. a. & \\
\hline & No metaphase & n. a. & $\mathrm{n}=0$ & n. a. & $\mathrm{n}=12$ \\
\hline
\end{tabular}

https://doi.org/10.1371/journal.pgen.1009779.t001

\section{The cenh3-4 allele does not promote the formation of haploid plants in crosses with wild type}

Interference with CENH3 function through structural rearrangements in the $\mathrm{N}$-terminal tail or amino acid substitutions in the conserved histone fold domain was shown to induce chromosome elimination and formation of haploid plants in Arabidopsis F1 crosses with wild type [40-43]. Some of the mutations were reported to decrease CENH3 levels, which suggested that downregulation of $\mathrm{CENH} 3$ could be sufficient to induce formation of haploid plants upon outcrossing $[41,44]$. To test this hypothesis, we pollinated cenh3-4 mutants with pollen from trichomeless gl1-1 plants. Haploid plants with this recessive mutant allele would be easily scored by their smooth leaf surface, in contrast to rough leaves in diploid hybrids. Out of $500 \mathrm{~F} 1$ plants, we identified only a single haploid plant validated by flow cytometry (S8 Fig). The frequency of haploid offspring (0.2\%) in cenh $3-4$ crosses is much lower than frequencies reported with mutations that alter the CENH3 amino acid sequence [40-43], suggesting that the decreased amount of CENH3 in cenh3-4 mutants is insufficient to trigger uniparental genome elimination in Arabidopsis.

\section{Discussion}

Transition from meiosis to post-meiotic differentiation of haploid gametophytes is governed by a dedicated mechanism that requires the nonsense-mediated RNA decay factor SMG7 [30]. So far, the only molecular function assigned to SMG7 was related to NMD, where SMG7 binds to phosphorylated UPF1 via its N-terminal phosphoserine binding domain and mediates relocalization of UPF1-bound RNA to P-bodies [45]. In vertebrates, the C-terminal region of SMG7 further associates with the CCR4-NOT deadenylase to degrade aberrant mRNA. This mechanism also appears to be conserved in plants [46,47]. Nonetheless, two lines of evidence argue that the meiotic function of SMG7 in Arabidopsis is not implemented through NMD. First, Arabidopsis UPF1-deficient plants are more impaired in NMD than SMG7-null mutants [48], but they do not show a meiotic phenotype and produce viable pollen [32]. Second, the hypomorphic smg7-6 allele carrying a T-DNA insertion in the C-terminal region is NMD-proficient, but still exhibits meiotic defects $[31,32]$. We therefore conclude that SMG7 has an additional role in regulating meiotic exit, at least in the male pathway.

We previously proposed that SMG7 directly or indirectly contributes to the downregulation of CDK activity at the end of meiosis [29]. Processes required for chromosome segregation, such as nuclear envelope breakdown, chromosome condensation, and spindle formation are driven by increasing activity of M-phase CDKs. Degradation of M-phase cyclins by the APC/C in anaphase and downregulation of CDKs revert these processes and allow cytokinesis, exit from the M-phase, and licensing of origins of replication for DNA synthesis in the next Sphase $[49,50]$. If CDK activity is not irreversibly downregulated, untimely chromosome re- 
condensation, spindle reassembly, and re-initiation of chromosome segregation might be consequences, as seen in $t d m 1$ and $s m g 7-6$. The complete lack of pollen in $t d m 1$ versus low numbers of viable pollen grains in $s m g 7-6$ could originate from differences in the degree of recondensation: less condensed chromatin in $t d m 1$ in the third division might preclude the formation of any chromosome cluster that would result in a functional microspore, while slightly stronger chromosome condensation at the respective state in $s m g 7-6$ could increase the chance of encapsulating the right chromosome combination for the occasional formation of viable pollen.

This residual fertility in smg7-6 permitted a suppressor screen to identify genes whose mutations affect meiotic exit in Arabidopsis and increase production of viable pollen and seeds. Identifying a mutation, twice independently, in the gene for centromeric histone CENH3 that partially rescues infertility of $s m g 7-6$ plants came as a surprise. CENH3 is the key determinant of centromeric chromatin and kinetochore assembly. Its inactivation in Arabidopsis is embryonic lethal [40], and RNAi-mediated knock down of CENH3 mRNA to 27$43 \%$ of the wild type level was reported to cause dwarfism and severe developmental defects [51]. Although the cenh3-4 mutation leads to a 10-fold reduction of fully spliced CENH3 mRNA and depletion of CENH3 from centromeres, mutant plants do not exhibit growth abnormalities under standard conditions and are fully fertile. Immunolocalization of CENH3 and the inner kinetochore proteins CENP-C and KNL2 suggest that centromeres and kinetochores are smaller in cenh3-4 plants compared to wild type. These data indicate that plants can tolerate a substantial decrease of CENH3 level and centromere size. This has also been shown for centromeres on supernumerary B-chromosomes in maize that retained their functionality despite being trimmed to approximately $100 \mathrm{~kb}$ via chromosome fission [52].

How does the decreased level of CENH3 contribute to the restored fertility of smg7-6 plants? The most notable cytological effect of the single cenh3-4 mutant was delayed congression of mitotic chromosomes to the metaphase plate, suggesting less efficient establishment of a stable bipolar spindle. Chromosome congression and the bipolar spindle are formed by a search-and-capture mechanism in which microtubules initially establish lateral contacts with kinetochores that are later transformed into more stable attachments to the plus ends of microtubules [53,54]. The small kinetochores in cenh3-4 mutants may decrease the efficiency of kinetochore-microtubule interaction and increase the time required for spindle formation. Such size-dependent attachment of kinetochores was predicted by computational modelling [54] and supported by the observation that chromosomes with larger kinetochores acquire bipolar orientation faster than chromosomes with smaller kinetochores [55]. Smaller kinetochores in the cenh3-4 smg7-6 double mutant PMCs could therefore reduce the degree or speed of aberrant meiotic divisions compared to $s m g 7-6$ single mutant plants. We propose that inefficient formation of centromere-microtubule interactions hinders spindle reassembly, re-entry into aberrant rounds of chromosome segregation, and thereby allows more efficient formation of viable pollen and higher fertility.

Centromere-mediated genome elimination is a promising strategy for inducing haploid plants for various breeding applications [56]. This technology was developed in Arabidopsis where all chromosomes of mutants with structurally altered CENH3 are eliminated upon crossing with wild type [40-42,57]. The underlying mechanism is assumed to be based on postzygotic incompatibility, whereby the parental chromosome set with the structurally altered CENH3 at its centromeres is mitotically unstable and therefore is left behind in early embryonic divisions $[40,58,59]$. It was hypothesized that CENH3 mutations may impair chromatin loading, forming smaller centromeres that cannot compete with the larger centromeres of the crossing parent [44], causing early loss of chromosomes due to size dimorphism of parental centromeres. Indeed, genome elimination can be induced in crosses between species with 
centromeres of different size, and by a CENH3 mutation that affects centromere loading $[41,44]$. Furthermore, haploid plants were generated in crosses with maize heterozygous for a cenh3 null mutation, suggesting that dilution of $\mathrm{CENH} 3$ during gametophytic divisions can render centromeres smaller or dysfunctional [60]. However, the substantially reduced level of CENH3 that, according to the immunocytological data, results in smaller centromeres and impaired mitotic spindles, was not efficient in haploid induction, at least in Arabidopsis cenh3-4 mutants. Notably, a comparably low frequency of Arabidopsis haploids was found after reducing the amount of wild-type $\mathrm{CENH} 3$ through female gametogenesis in plants heterozygous for the cenh3-1 null mutation [61]. Also in wheat, multiple knock-outs of homeologous $\mathrm{CENH} 3$ genes are insufficient to induce haploid plants unless combined with a hypomorphic mutation containing a short deletion in the CENH3 $\mathrm{N}$-terminal domain [62]. Thus, the efficiency of centromere-mediated genome elimination may depend on the extent and combined effects of qualitative and quantitative changes in centromere structure.

\section{Methods}

\section{Plant material and growth conditions}

Arabidopsis thaliana ecotype Columbia (Col-0) and mutant seeds were grown on soil in growth chambers at $21^{\circ} \mathrm{C}$ at $50-60 \%$ humidity under $16 \mathrm{~h} / 8 \mathrm{~h}$ light/dark cycles. The following mutant lines were used in this study: smg7-6 [32], smg7-1, smg7-3 [30], gl1-1 derived from tert line [63]. The $t d m$ 1-4 mutant was obtained from NASC (SALK_123139) and PCR-genotyped using PCR primers described in $\mathrm{S} 1$ Table. Plants used for live cell imaging were generated by introgression of reporter constructs from HTA10:RFP [33] and pRPS5A::TagRFP:TUB4 [22] lines. Root growth assay was performed by growing surface-sterilized seeds on vertically oriented MS agar plates (0.7\% plant agar, Duchefa Biochemie) at $21^{\circ} \mathrm{C}$ under $16 \mathrm{~h} / 8 \mathrm{~h} \mathrm{light} /$ dark photoperiods. The position of the root tip was marked 5, 8 and 10 days after germination to determine the root growth rate.

\section{Assessment of plant fertility}

Pollen viability was determined by Alexander staining as described [64]. Silique length was measured when apical meristems ceased forming new flowers. Average silique length was calculated at each position for the first 40 siliques along the main inflorescence bolt (numbered with 1 for the oldest and 40 for the youngest silique).

\section{Genetic screening}

Seeds from $s m g 7-6$ plants were incubated in $50 \mathrm{ml}$ of water at $4^{\circ} \mathrm{C}$ overnight. Water was replaced with $50 \mathrm{ml}$ of $0.3 \%(\mathrm{v} / \mathrm{v})$ ethyl-methanesulfonate (EMS) in water and incubated for 8 $\mathrm{h}$ at room temperature in the dark with gentle shaking. The EMS solution was replaced with water and the seeds were incubated for 3 days at $4^{\circ} \mathrm{C}$ in the dark. Twelve seeds were sown per pot $(9 \mathrm{x} 9 \mathrm{~cm})$ and $\mathrm{M} 2$ seeds were pooled from all plants in one pot. Around $100 \mathrm{M} 2$ seeds from each pool were grown and manually scored for improved fertility compared to smg7-6 mutants grown in parallel. The genetic transmissibility of restored fertility was confirmed in the M3 generation and M3 plants were backcrossed to the parental $s m g 7-6$ line to create B2 mapping populations. Inflorescences from segregants with improved fertility in B2 were pooled (at least 50 plants per line) for DNA extraction using the CTAB (cetyltrimethyl ammonium bromide) method [65]. DNA (2 $\mu \mathrm{g}$ ) was sheared in a S220 Focused-ultrasonicator (Covaris), DNA fragments were purified using the DNA Clean \&Concentrator-5 kit (Zymo Research), and quantified using the Quant-iT PicoGreen dsDNA Reagent (Thermo Fisher Scientific). After 
analyzing the samples for proper fragmentation ( $150 \mathrm{bp})$ in an Agilent 2100 Bioanalyser System (Agilent Technologies), DNA libraries were prepared using $300 \mathrm{ng}$ of fragmented DNA following the instructions of the NEBNext Ultra II DNA Library Prep kit (New England Biolabs). Samples were sequenced on a HiSeq 2500 (Illumina) with the sequencing output of single ends with 100 nucleotides in size. Mutations associated with improved fertility were identified using ArtMAP software [34]. For further genetic experiments, the identified cenh3-4 mutation was PCR-genotyped by the Derived Cleaved Amplified Polymorphic Sequences (dCAPS) method using primers described in S1 Table. The PCR product was cleaved with PstI and separated in $2 \%(\mathrm{w} / \mathrm{v})$ high-resolution agarose in TBE buffer. The amplicon of the wild type allele remained uncleaved with a size of $222 \mathrm{bp}$, while that of the cenh3-4 allele was cut into $188 \mathrm{bp}$ and $34 \mathrm{bp}$ fragments.

\section{Cytology}

Staining of PMCs in whole anthers was performed as previously described [66] with the following modifications: inflorescences were fixed in PEM buffer (50 mM Pipes pH 6.9, $5 \mathrm{mM}$ EGTA pH 8.0, 5 mM MgSO4, 0.1\% Triton X100) supplemented with 4\% formaldehyde by 15 min vacuum infiltration and $45 \mathrm{~min}$ incubation at room temperature. Inflorescences were washed $3 \mathrm{x}$ with PEM buffer and buds smaller than $0.6 \mathrm{~mm}$ were dissected, transferred to $100 \mu \mathrm{l}$ of PEM supplemented with DAPI $(5 \mu \mathrm{g} / \mathrm{ml})$, and stained for $1 \mathrm{~h}$ in the dark. Anthers were washed twice with $1 \mathrm{ml}$ of PEM buffer for $5 \mathrm{~min}$, then incubated in PEM buffer at $60^{\circ} \mathrm{C}$ for $10 \mathrm{~min}$ and at $4^{\circ} \mathrm{C}$ for $10 \mathrm{~min}$. Anthers were washed once, mounted in Vectashield (Vector Laboratories), covered with cover slips, and examined on an LSM700 or LSM880 confocal microscope (Zeiss). Immunodetection of microtubules in pollen mother cells was performed using rat anti- $\alpha$-tubulin antibody (Serotec) as previously described [29]. The same protocol was applied to detect CENH3 with a custom-made (LifeTein, https://www.lifetein.com) polyclonal antisera raised against the N-terminal peptide of CenH3 [67] and anti-Rabbit-Alexa Fluor 488 (ThermoFisher Scientific). KNL2, MIS12 and CENP-C were detected in root nuclei as previously described [68] using custom made anti-AtKNL2 (dilution 1:2000) [38], antiMIS12 (1:1000) or anti-AtCENP-C (1:300) antibodies (http://www.eurogentec.com/) [51] and goat anti-rabbit rhodamine (Jackson Immuno Research Laboratories). DNA content in nuclei of haploid plants was determined by flow cytometry as previously described [69].

\section{Live cell imaging}

Live cell imaging of spindles in PMCs was performed with the pRPS5A::TagRFP:TUB4 marker [22] using a protocol developed for light sheet microscopy [33]. Briefly, the floral buds were embedded in 5MS ( $5 \%$ sucrose $+1 / 2$ MS, Murashige \& Skoog Medium including vitamins and MES buffer, Duchefa Biochemie) supplemented with 1\% low gelling agarose (Sigma Aldrich) in a glass capillary (size 4, Brand). The capillary was mounted in the metal holder of the Light sheet Z.1 microscope (Zeiss), the agarose with the embedded floral bud was partially pushed out from the glass capillary into the microscopy chamber containing 5MS media, and imaged in Light sheet Z.1 microscope using 10x objective (Detection optics 10x/0.5), single illumination (Illumination Optics 10x/0.2), $561 \mathrm{~nm}$ laser (15\% intensity) in $5 \mathrm{~min}$ time increments. The image data were processed by ZEN Blue software (Zeiss). Live cell imaging of mitosis in roots was performed with the HTA10:RFP marker as follows: surface-sterilized seeds were germinated on $1 \mathrm{ml}$ of $1 \frac{1}{2} \mathrm{MS}$ medium with $0.8 \%$ phyto-agar (Duchefa Biochemie) in petri dishes with a glass bottom (MatTek corporation). Once growing roots reached the glass bottom, they were imaged with an LSM780 inverted confocal microscope (Zeiss, 40x objective) in $1 \mathrm{~min}$ 
intervals. Two $\mathrm{ml}$ of $2 \mu \mathrm{M}$ oryzalin solution were added to plates $10 \mathrm{~min}$ before imaging. Images were processed using Zen Black (Zeiss).

\section{Chromatin immunoprecipitation}

ChIP experiments were performed from 10 day old seedlings with chromatin sheared to approximately $500 \mathrm{bp}$ fragments by sonication according to a previously described protocol [70]. Five $\mu \mathrm{l}$ of anti-histone $\mathrm{H} 3$ antibody ( $1 \mathrm{mg} / \mathrm{ml}$; ab1791; Abcam), and $10 \mu \mathrm{l}$ of anti-CENH3 antibody were used. Detection of centromeric 180 bp satellite DNA was performed by dot-blot hybridization as well as by qPCR. For dot-blot hybridization, $40 \mu \mathrm{l}$ from $50 \mu \mathrm{l}$ samples were combined with $10 \mu \mathrm{l}$ of MILI-Q water and $6 \mu \mathrm{l}$ of $3 \mathrm{M} \mathrm{NaOH}$, incubated for $1 \mathrm{~h}$ at $65^{\circ} \mathrm{C}$ and dot-blotted on Amersham HybondTM-XL membrane (GE Healthcare). DNA was fixed by UV using a UV crosslinker BLX-254 (Analytik Jena). After prehybridization at $65^{\circ} \mathrm{C}$ for $2 \mathrm{~h}$ in hybridization buffer (7\% SDS, $0.25 \mathrm{M}$ sodium-phosphate buffer $\mathrm{pH}$ 7.2), membranes were hybridized at $65^{\circ} \mathrm{C}$ overnight with denatured probes generated by Klenow-labeling of an Arabidopsis centromere 180 bp satellite fragment with $\alpha^{32} \mathrm{P}$ dATP (DecaLabel DNA Labeling Kit, Thermo Scientific). The fragment was prepared by PCR amplification of Arabidopsis genomic DNA using the primer combination CEN-1 ATCAAGTCATATTCGACTCCA and CEN-2 CTCATGTGTATGATTGAGAT, followed by purification (NucleoSpin Gel and PCR Cleanup, Macherey-Nagel). Membranes were washed twice with 2x SSC, $0.1 \%$ SDS at RT for 5 min and twice with $0.2 \mathrm{x}$ SSC, $0.1 \%$ SDS at $65^{\circ} \mathrm{C}$ for $15 \mathrm{~min}$. Membranes were wrapped in Saran wrap and exposed to a phospho-screen which was scanned with a Typhoon FLA 7000 (GE Healthcare). Signals were quantified using ImageQuant software (GE Healthcare). For qPCR quantification, $1 \mu \mathrm{l}$ from $50 \mu \mathrm{l}$ samples was used in a $20 \mu \mathrm{l} \mathrm{qPCR}$ reaction containing 1x LightCycler 480 High Resolution Melting Master mix, $3 \mathrm{mM} \mathrm{MgCl}$, and $0.25 \mu \mathrm{M}$ of each primer CEN-f CCGTATGAGTCTTTGGCTTTG and CEN-r TTGGTTAGTGTTTTGGAGTCG. Reactions were performed in technical triplicates and quantified as percent of input.

\section{Western blot analysis}

For nuclei purification, $300 \mathrm{mg}$ of inflorescences were collected in $15 \mathrm{ml}$ Falcon tubes, frozen in liquid nitrogen, and homogenized with metal beads by vortexing. The disrupted tissue was resuspended in $5 \mathrm{ml}$ of nuclei isolation buffer (NIB) (10 mM MES-KOH pH 5.3, $10 \mathrm{mM} \mathrm{NaCl}$, $10 \mathrm{mM} \mathrm{KCl}, 250 \mathrm{mM}$ sucrose, $2.5 \mathrm{mM}$ EDTA, $2.5 \mathrm{mM}$ ß-mercaptoethanol, $0.1 \mathrm{mM}$ spermine, $0.1 \mathrm{mM}$ spermidine, $0.3 \%$ Triton X-100), and filtered through two layers of Miracloth into a $50 \mathrm{ml}$ Falcon tube. Nuclei were pelleted by centrifugation, resuspended in $1 \mathrm{ml} \mathrm{NIB}$ and collected again by centrifugation. The pellet was resuspended in $150 \mu \mathrm{l}$ of $\mathrm{N}$ buffer $(250 \mathrm{mM}$ sucrose, $15 \mathrm{mM}$ Tris- $\mathrm{HCl} \mathrm{pH}$ 7.5, $60 \mathrm{mM} \mathrm{KCl}, 15 \mathrm{mM} \mathrm{NaCl}, 5 \mathrm{mM} \mathrm{MgCl} 2,1 \mathrm{mM} \mathrm{CaCl}_{2}, 1$ $\mathrm{mM}$ DTT, $10 \mathrm{mM}$ B-glycerophosphate, protease inhibitors). Nuclei were lysed by adding $40 \mu \mathrm{l}$ $5 \mathrm{x}$ Laemmli loading buffer (Sigma) and boiling for $5 \mathrm{~min} .40 \mu \mathrm{g}$ of nuclear protein was separated by SDS-polyacrylamide gel electrophoresis. Separated proteins were transferred to PVDF membranes (Thermo Scientific) by electroblotting. The membranes were incubated in low-fat milk with rabbit anti-CENH3 antibody (1:5,000; ab72001; Abcam) for $12 \mathrm{~h}$ at $4^{\circ} \mathrm{C}$. Secondary anti-rabid-HPR conjugated antibody was diluted (1:5000) and incubated for $2 \mathrm{~h}$. TBST (25 mM Tris-Cl, pH 7.5, $150 \mathrm{mM} \mathrm{NaCl}, 0.05 \%$ Tween-20, pH 7.5) was used to wash the membranes and the signal was detected using ECL Western Blotting Substrate (Pierce).

\section{RNA analysis}

RNA was isolated from inflorescences using the RNeasy Plant Mini Kit (Qiagen). Samples were treated with TURBO DNA-free Kit (Ambion) to remove contaminants from genomic 
DNA. cDNA was synthetized from $5 \mu \mathrm{g}$ of RNA with the Maxima H Minus First Strand cDNA Synthesis Kit (Thermo Scientific) and oligo (dT)18 primer. cDNA was used as a template for quantitative PCR reactions using the FastStart Essential DNA Green Master (Roche) and transcript-specific primer pairs (S1 Table) on the LightCycler 96 System (Roche). The $\Delta \Delta \mathrm{Ct}$ method was used to calculate the relative quantification of transcripts [71]. MON1 (AT2G28390) was used as reference gene, and transcript levels for each genotype were normalized to wild type controls.

\section{Supporting information}

S1 Movie. Live imaging of $p R P S 5 A:$ TagRFP:TUB4 tubulin marker during the first and second meiotic division in wild a type plant. (MP4)

S2 Movie. Live imaging of pRPS5A::TagRFP:TUB4 tubulin marker during regular meiotic divisions and two postmeiotic spindle reassembly cycles in smg7-6 mutants. (MP4)

S3 Movie. Live imaging of $p R P S 5 A$ ::TagRFP:TUB4 tubulin marker from the $3^{\text {rd }}$ to $6^{\text {th }}$ cycle of spindle reassembly in $s m g$ 7-6 mutants.

(MP4)

S4 Movie. Live imaging of HTA10:RFP chromatin marker during mitosis in a root tip of a wild type plant.

(AVI)

S5 Movie. Live imaging of HTA10:RFP chromatin marker during mitosis in a root tip of a cenh3-2 mutant.

(AVI)

S6 Movie. Live imaging of HTA10:RFP chromatin marker during mitosis in a oryzalin treated root tip of a wild type plant.

(AVI)

S7 Movie. Live imaging of HTA10:RFP chromatin marker during mitosis in a oryzalin treated root tip of a cenh3-2 mutant. (AVI)

S1 Fig. Allelic series of Arabidopsis smg7 mutants. (A) Five week-old Arabidopsis mutants homozygous for the indicated alleles. (B) Quantitative RT-PCR analysis of SMG7 mRNA from the region located upstream of the T-DNA insertions and of transcripts targeted by NMD in smg7-1 and smg7-6 mutants. Two mRNA splice variants, one containing a premature termination codon (PTC+), were quantified for the AT2G45670 locus. Error bars indicate standard deviations from three biological replicas.

S2 Fig. Female fertility in smg7-6 mutants. (A) Siliques from wild type and smg7-6 plants produced by pollination with wild type pollen. Scale bar $=0.5 \mathrm{~cm}$. (B) Box-plot diagrams showing quantification of seed count per silique from wild type $(\mathrm{N}=14)$ and $s m g 7-6$ plants pollinated with wild type pollen. Yield from siliques at positions 1 to $15(\mathrm{~N}=136)$ and 20 to 35 $(\mathrm{N}=153)$ is indicated for $s m g 7-6$ mutants. $(\mathrm{C})$ Box-plot diagram showing quantification of seeds in siliques at indicating positions along the main inflorescence bolt with 1 indicating the lowest position. 5 to 14 siliques were counted per position.

(TIF) 
S3 Fig. Genetic complementation of smg7-6 mutation with the endogenous pSMG7::SMG7 gene construct. Anthers from 10 independent T1 smg7-6 transformants carrying the pSMG7:: $S M G 7$ construct with viable pollen detected by Alexander staining. All T1 lines show a restoration of viable pollen.

(TIF)

S4 Fig. Epistatic analysis of $s m g$ 7-6 and $t \boldsymbol{d} m$ 1-4 mutations. (A) Anthers of the indicated mutants after Alexander staining. Viable pollen stain red. (B) Meiotic progression in PMCs of smg7-6 tdm1-4 double mutants. Spindles are stained with anti- $\alpha$-tubulin antibody (red), DNA is counterstained with DAPI. Scale bar corresponds to $5 \mu \mathrm{m}$. (TIF)

S5 Fig. Association mapping of de novo mutations with the smg7-6 suppressor trait in EMS30 and EMS155 lines. (A) Genome-wide distribution of de novo mutations and their frequency in fertile B2plants generated from backcrosses of EMS30 and EMS155 lines with parental smg7-6 plants. (B) De novo mutations at the left arm of chromosome 1 in the EMS30 and EMS155 lines. Coordinates of these mutations in TAIR10 annotation are indicated. (TIF)

S6 Fig. Immunodetection of CENH3 in prophase I using the same imaging conditions. CENH3 is visualized with CENH3 antibody; DNA is counterstained with DAPI (blue). Scale bar represents $5 \mu \mathrm{m}$.

(TIF)

S7 Fig. Immunodetection of CENH3 in leaf (A) and root (B) nuclei. CENH3 is visualized with CENH3 antibody; DNA is counterstained with DAPI (blue). Scale bar represents $5 \mu \mathrm{m}$. (TIF)

S8 Fig. Haploid plant obtained from the cross between cenh3-2 and gl1-1 Col-0. (A) The haploid plant (indicated by arrowhead) was recognized based on its trichomeless phenotype. (B) Nuclear content of inflorescence nuclei from the haploid and a parent plant determined by flow cytometry.

(TIF)

S1 Table. Primers used in this study. (XLSX)

S2 Table. Numerical data underlying presented graphs. (XLSX)

\section{Acknowledgments}

We thank to Arp Schnittger for providing the pRPS5A::TagRFP:TUB4 line, Sona Valuchova for help with image processing, and Andreas Houben for helpful discussion. The genome sequencing was performed by the Next Generation Sequencing Facility at Vienna BioCenter Core Facilities (VBCF), member of the Vienna BioCenter (VBC), Austria. We also acknowledge the Plant Sciences Facility at Vienna BioCenter Core Facilities (VBCF), and the Plant Sciences Core Facility of CEITEC MU for support with plant cultivation. Microscopy was performed in the BioOptics facility at the IMP, and the core facility CELLIM of CEITEC. 


\section{Author Contributions}

Conceptualization: Claudio Capitao, Ortrun Mittelsten Scheid, Karel Riha.

Formal analysis: Claudio Capitao, Jaroslav Fulnecek.

Funding acquisition: Inna Lermontova, Ortrun Mittelsten Scheid, Karel Riha.

Investigation: Claudio Capitao, Sorin Tanasa, Jaroslav Fulnecek, Vivek K. Raxwal, Svetlana Akimcheva, Petra Bulankova, Lucie Crhak Khaitova, Manikandan Kalidass, Inna Lermontova.

Methodology: Pavlina Mikulkova.

Project administration: Ortrun Mittelsten Scheid, Karel Riha.

Resources: Inna Lermontova.

Supervision: Inna Lermontova, Ortrun Mittelsten Scheid, Karel Riha.

Visualization: Claudio Capitao, Sorin Tanasa, Jaroslav Fulnecek, Lucie Crhak Khaitova, Manikandan Kalidass, Karel Riha.

Writing - original draft: Karel Riha.

Writing - review \& editing: Claudio Capitao, Inna Lermontova, Ortrun Mittelsten Scheid.

\section{References}

1. Marston AL, Amon A. Meiosis: cell-cycle controls shuffle and deal. Nat Rev Mol Cell Biol. 2004; 5 (12):983-97. https://doi.org/10.1038/nrm1526 PMID: 15573136.

2. Petronczki M, Siomos MF, Nasmyth K. Un menage a quatre: the molecular biology of chromosome segregation in meiosis. Cell. 2003; 112(4):423-40. https://doi.org/10.1016/s0092-8674(03)00083-7 PMID: 12600308.

3. Mirzaghaderi G, Horandl E. The evolution of meiotic sex and its alternatives. Proc Biol Sci. 2016; 283 (1838). Epub 2016/09/09. https://doi.org/10.1098/rspb.2016.1221 PMID: 27605505.

4. Bowman JL, Sakakibara K, Furumizu C, Dierschke T. Evolution in the Cycles of Life. Annu Rev Genet. 2016; 50:133-54. Epub 2016/09/13. https://doi.org/10.1146/annurev-genet-120215-035227 PMID: 27617970.

5. Yang WC, Ye D, Xu J, Sundaresan V. The SPOROCYTELESS gene of Arabidopsis is required for initiation of sporogenesis and encodes a novel nuclear protein. Genes Dev. 1999; 13(16):2108-17. Epub 1999/08/31. https://doi.org/10.1101/gad.13.16.2108 PMID: 10465788.

6. Nonomura K, Eiguchi M, Nakano M, Takashima K, Komeda N, Fukuchi S, et al. A novel RNA-recognition-motif protein is required for premeiotic G1/S-phase transition in rice (Oryza sativa L.). PLoS Genet. 2011; 7(1):e1001265. Epub 2011/01/22. https://doi.org/10.1371/journal.pgen.1001265 PMID: 21253568.

7. Mercier R, Vezon D, Bullier E, Motamayor JC, Sellier A, Lefevre F, et al. SWITCH1 (SWI1): a novel protein required for the establishment of sister chromatid cohesion and for bivalent formation at meiosis. Genes Dev. 2001; 15(14):1859-71. https://doi.org/10.1101/gad.203201 PMID: 11459834.

8. Pawlowski WP, Wang CJ, Golubovskaya IN, Szymaniak JM, Shi L, Hamant O, et al. Maize AMEIOTIC1 is essential for multiple early meiotic processes and likely required for the initiation of meiosis. Proc Natl Acad Sci U S A. 2009; 106(9):3603-8. https://doi.org/10.1073/pnas.0810115106 PMID: 19204280.

9. Zhao X, Bramsiepe J, Van Durme M, Komaki S, Prusicki MA, Maruyama D, et al. RETINOBLASTOMA RELATED1 mediates germline entry in Arabidopsis. Science. 2017; 356(6336). https://doi.org/10.1126/ science.aaf6532 PMID: 28450583.

10. Kelliher T, Walbot V. Hypoxia triggers meiotic fate acquisition in maize. Science. 2012; 337(6092):3458. Epub 2012/07/24. https://doi.org/10.1126/science.1220080 PMID: 22822150.

11. Nonomura K, Morohoshi A, Nakano M, Eiguchi M, Miyao A, Hirochika $\mathrm{H}$, et al. A germ cell specific gene of the ARGONAUTE family is essential for the progression of premeiotic mitosis and meiosis during sporogenesis in rice. Plant Cell. 2007; 19(8):2583-94. Epub 2007/08/07. https://doi.org/10.1105/tpc. 107.053199 PMID: 17675402. 
12. Olmedo-Monfil V, Duran-Figueroa N, Arteaga-Vazquez M, Demesa-Arevalo E, Autran D, Grimanelli D, et al. Control of female gamete formation by a small RNA pathway in Arabidopsis. Nature. 2010; 464 (7288):628-32. Epub 2010/03/09. https://doi.org/10.1038/nature08828 PMID: 20208518.

13. Yuan TL, Huang WJ, He J, Zhang D, Tang WH. Stage-Specific Gene Profiling of Germinal Cells Helps Delineate the Mitosis/Meiosis Transition. Plant Physiol. 2018; 176(2):1610-26. Epub 2017/12/01. https://doi.org/10.1104/pp.17.01483 PMID: 29187566.

14. Nelms B, Walbot $V$. Defining the developmental program leading to meiosis in maize. Science. 2019; 364(6435):52-6. https://doi.org/10.1126/science.aav6428 PMID: 30948545.

15. Dissmeyer N, Nowack MK, Pusch S, Stals H, Inze D, Grini PE, et al. T-loop phosphorylation of Arabidopsis CDKA; 1 is required for its function and can be partially substituted by an aspartate residue. Plant Cell. 2007; 19(3):972-85. https://doi.org/10.1105/tpc.107.050401 PMID: 17369369.

16. Sofroni K, Takatsuka H, Yang C, Dissmeyer N, Komaki S, Hamamura Y, et al. CDKD-dependent activation of CDKA; 1 controls microtubule dynamics and cytokinesis during meiosis. J Cell Biol. 2020; 219(8). Epub 2020/07/02. https://doi.org/10.1083/jcb.201907016 PMID: 32609301.

17. Yang C, Sofroni K, Wijnker E, Hamamura Y, Carstens L, Harashima H, et al. The Arabidopsis Cdk1/ Cdk2 homolog CDKA;1 controls chromosome axis assembly during plant meiosis. EMBO J. 2020; 39 (3):e101625. Epub 2019/09/27. https://doi.org/10.15252/embj.2019101625 PMID: 31556459.

18. Wijnker E, Harashima H, Muller K, Parra-Nunez $P$, de Snoo CB, van de Belt J, et al. The Cdk1/Cdk2 homolog CDKA; 1 controls the recombination landscape in Arabidopsis. Proc Natl Acad Sci U S A. 2019; 116(25):12534-9. Epub 2019/06/06. https://doi.org/10.1073/pnas.1820753116 PMID: 31164422.

19. Bulankova $P$, Akimcheva S, Fellner N, Riha K. Identification of Arabidopsis meiotic cyclins reveals functional diversification among plant cyclin genes. PLoS Genet. 2013; 9(5):e1003508. Epub 2013/05/15. https://doi.org/10.1371/journal.pgen.1003508 PMID: 23671425.

20. Azumi Y, Liu D, Zhao D, Li W, Wang G, Hu Y, et al. Homolog interaction during meiotic prophase I in Arabidopsis requires the SOLO DANCERS gene encoding a novel cyclin-like protein. Embo J. 2002; 21 (12):3081-95. https://doi.org/10.1093/emboj/cdf285 PMID: 12065421.

21. Wang Y, Magnard JL, McCormick S, Yang M. Progression through meiosis I and meiosis II in Arabidopsis anthers is regulated by an A-type cyclin predominately expressed in prophase I. Plant Physiol. 2004; 136(4):4127-35. https://doi.org/10.1104/pp.104.051201 PMID: 15557098.

22. Prusicki MA, Keizer EM, van Rosmalen RP, Komaki S, Seifert F, Muller K, et al. Live cell imaging of meiosis in Arabidopsis thaliana. Elife. 2019; 8. https://doi.org/10.7554/eLife.42834 PMID: 31107238.

23. d'Erfurth I, Cromer L, Jolivet S, Girard C, Horlow C, Sun Y, et al. The cyclin-A CYCA1;2/TAM is required for the meiosis I to meiosis II transition and cooperates with OSD1 for the prophase to first meiotic division transition. PLoS Genet. 2010; 6(6):e1000989. https://doi.org/10.1371/journal.pgen.1000989 PMID: 20585549.

24. Cromer L, Heyman J, Touati S, Harashima H, Araou E, Girard C, et al. OSD1 promotes meiotic progression via APC/C inhibition and forms a regulatory network with TDM and CYCA1;2/TAM. PLoS Genet. 2012; 8(7):e1002865. Epub 2012/07/31. https://doi.org/10.1371/journal.pgen.1002865 PMID: 22844260.

25. Ross KJ, Fransz P, Armstrong SJ, Vizir I, Mulligan B, Franklin FC, et al. Cytological characterization of four meiotic mutants of Arabidopsis isolated from T-DNA-transformed lines. Chromosome Res. 1997; 5 (8):551-9. https://doi.org/10.1023/a:1018497804129 PMID: 9451956.

26. Glover J, Grelon M, Craig S, Chaudhury A, Dennis E. Cloning and characterization of MS5 from Arabidopsis: a gene critical in male meiosis. Plant J. 1998; 15(3):345-56. https://doi.org/10.1046/j.1365313x.1998.00216.x PMID: 9750346.

27. Sanders PM, Bui AQ, Weterings K, Mclntire KN, Hsu YC, Lee PY, et al. Anther developmental defects in Arabidopsis thaliana male-sterile mutants. Sex Plant Reprod. 1999; 11:297-322.

28. Cifuentes M, Jolivet S, Cromer L, Harashima H, Bulankova P, Renne C, et al. TDM1 Regulation Determines the Number of Meiotic Divisions. PLoS Genet. 2016; 12(2):e1005856. https://doi.org/10.1371/ journal.pgen.1005856 PMID: 26871453.

29. Bulankova P, Riehs-Kearnan N, Nowack MK, Schnittger A, Riha K. Meiotic progression in Arabidopsis is governed by complex regulatory interactions between SMG7, TDM1, and the meiosis I-specific cyclin TAM. Plant Cell. 2010; 22(11):3791-803. https://doi.org/10.1105/tpc.110.078378 PMID: 21119056.

30. Riehs N, Akimcheva S, Puizina J, Bulankova P, Idol RA, Siroky J, et al. Arabidopsis SMG7 protein is required for exit from meiosis. J Cell Sci. 2008; 121(Pt 13):2208-16. https://doi.org/10.1242/jcs.027862 PMID: 18544632 
31. Capitao C, Shukla N, Wandrolova A, Mittelsten Scheid O, Riha K. Functional Characterization of SMG7 Paralogs in Arabidopsis thaliana. Front Plant Sci. 2018; 9:1602. https://doi.org/10.3389/fpls.2018. 01602 PMID: 30459790.

32. Riehs-Kearnan N, Gloggnitzer J, Dekrout B, Jonak C, Riha K. Aberrant growth and lethality of Arabidopsis deficient in nonsense-mediated RNA decay factors is caused by autoimmune-like response. Nucleic Acids Res. 2012; 40(12):5615-24. Epub 2012/03/02. https://doi.org/10.1093/nar/gks195 PMID: 22379136.

33. Valuchova S, Mikulkova P, Pecinkova J, Klimova J, Krumnikl M, Bainar P, et al. Imaging plant germline differentiation within Arabidopsis flowers by light sheet microscopy. Elife. 2020; 9. Epub 2020/02/12. https://doi.org/10.7554/eLife.52546 PMID: 32041682.

34. Javorka P, Raxwal VK, Najvarek J, Riha K. artMAP: A user-friendly tool for mapping ethyl methanesulfonate-induced mutations in Arabidopsis. Plant Direct. 2019; 3(6):e00146. Epub 2019/06/28. https://doi. org/10.1002/pld3.146 PMID: 31245783.

35. Lermontova I, Schubert V, Fuchs J, Klatte S, Macas J, Schubert I. Loading of Arabidopsis centromeric histone CENH3 occurs mainly during G2 and requires the presence of the histone fold domain. Plant Cell. 2006; 18(10):2443-51. https://doi.org/10.1105/tpc.106.043174 PMID: 17028205.

36. Ogura $\mathrm{Y}$, Shibata F, Sato H, Murata M. Characterization of a CENP-C homolog in Arabidopsis thaliana. Genes Genet Syst. 2004; 79(3):139-44. Epub 2004/08/27. https://doi.org/10.1266/ggs.79.139 PMID: 15329494.

37. Sato H, Shibata F, Murata M. Characterization of a Mis12 homologue in Arabidopsis thaliana. Chromosome Res. 2005; 13(8):827-34. https://doi.org/10.1007/s10577-005-1016-3 PMID: 16331414.

38. Lermontova I, Kuhlmann M, Friedel S, Rutten T, Heckmann S, Sandmann M, et al. Arabidopsis kinetochore null2 is an upstream component for centromeric histone $\mathrm{H} 3$ variant cenH3 deposition at centromeres. Plant Cell. 2013; 25(9):3389-404. Epub 2013/09/10. https://doi.org/10.1105/tpc.113.114736 PMID: 24014547.

39. Morejohn LC, Bureau TE, Mole-Bajer J, Bajer AS, Fosket DE. Oryzalin, a dinitroaniline herbicide, binds to plant tubulin and inhibits microtubule polymerization in vitro. Planta. 1987; 172(2):252-64. Epub 1987/10/01. https://doi.org/10.1007/BF00394595 PMID: 24225878.

40. Ravi M, Chan SW. Haploid plants produced by centromere-mediated genome elimination. Nature. 2010; 464(7288):615-8. https://doi.org/10.1038/nature08842 PMID: 20336146.

41. Karimi-Ashtiyani R, Ishii T, Niessen M, Stein N, Heckmann S, Gurushidze M, et al. Point mutation impairs centromeric CENH3 loading and induces haploid plants. Proc Natl Acad Sci U S A. 2015; 112 (36):11211-6. Epub 2015/08/22. https://doi.org/10.1073/pnas.1504333112 PMID: 26294252.

42. Kuppu S, Tan EH, Nguyen H, Rodgers A, Comai L, Chan SW, et al. Point Mutations in Centromeric Histone Induce Post-zygotic Incompatibility and Uniparental Inheritance. PLoS Genet. 2015; 11(9): e1005494. Epub 2015/09/10. https://doi.org/10.1371/journal.pgen.1005494 PMID: 26352591.

43. Kuppu S, Ron M, Marimuthu MPA, Li G, Huddleson A, Siddeek MH, et al. A variety of changes, including CRISPR/Cas9-mediated deletions, in CENH3 lead to haploid induction on outcrossing. Plant Biotechnol J. 2020. Epub 2020/02/26. https://doi.org/10.1111/pbi.13365 PMID: 32096293.

44. Wang N, Dawe RK. Centromere Size and Its Relationship to Haploid Formation in Plants. Mol Plant. 2018; 11(3):398-406. Epub 2017/12/27. https://doi.org/10.1016/j.molp.2017.12.009 PMID: 29277426.

45. Unterholzner L, Izaurralde E. SMG7 acts as a molecular link between mRNA surveillance and mRNA decay. Mol Cell. 2004; 16(4):587-96. https://doi.org/10.1016/j.molcel.2004.10.013 PMID: 15546618.

46. Loh B, Jonas S, Izaurralde E. The SMG5-SMG7 heterodimer directly recruits the CCR4-NOT deadenylase complex to mRNAs containing nonsense codons via interaction with POP2. Genes Dev. 2013; 27 (19):2125-38. https://doi.org/10.1101/gad.226951.113 PMID: 24115769.

47. Merai Z, Benkovics AH, Nyiko T, Debreczeny M, Hiripi L, Kerenyi Z, et al. The late steps of plant nonsense-mediated mRNA decay. Plant J. 2012. Epub 2012/09/15. https://doi.org/10.1111/tpj.12015 PMID: 22974464.

48. Raxwal VK, Simpson CG, Gloggnitzer J, Entinze JC, Guo W, Zhang R, et al. Nonsense-Mediated RNA Decay Factor UPF1 Is Critical for Posttranscriptional and Translational Gene Regulation in Arabidopsis. Plant Cell. 2020; 32(9):2725-41. Epub 2020/07/16. https://doi.org/10.1105/tpc.20.00244 PMID: 32665305.

49. Lopez-Aviles S, Kapuy O, Novak B, Uhlmann F. Irreversibility of mitotic exit is the consequence of systems-level feedback. Nature. 2009; 459(7246):592-5. Epub 2009/04/24. https://doi.org/10.1038/ nature07984 PMID: 19387440.

50. Potapova TA, Daum JR, Pittman BD, Hudson JR, Jones TN, Satinover DL, et al. The reversibility of mitotic exit in vertebrate cells. Nature. 2006; 440(7086):954-8. https://doi.org/10.1038/nature04652 PMID: 16612388. 
51. Lermontova I, Koroleva O, Rutten T, Fuchs J, Schubert V, Moraes I, et al. Knockdown of CENH3 in Arabidopsis reduces mitotic divisions and causes sterility by disturbed meiotic chromosome segregation. Plant J. 2011; 68(1):40-50. Epub 2011/06/04. https://doi.org/10.1111/j.1365-313X.2011.04664.x PMID: 21635586

52. Jin W, Lamb JC, Vega JM, Dawe RK, Birchler JA, Jiang J. Molecular and functional dissection of the maize B chromosome centromere. Plant Cell. 2005; 17(5):1412-23. https://doi.org/10.1105/tpc.104. 030643 PMID: 15805482.

53. Tanaka K, Mukae N, Dewar H, van Breugel M, James EK, Prescott AR, et al. Molecular mechanisms of kinetochore capture by spindle microtubules. Nature. 2005; 434(7036):987-94. https://doi.org/10.1038/ nature03483 PMID: 15846338.

54. Magidson V, Paul R, Yang N, Ault JG, O'Connell CB, Tikhonenko I, et al. Adaptive changes in the kinetochore architecture facilitate proper spindle assembly. Nat Cell Biol. 2015; 17(9):1134-44. Epub 2015/ 08/11. https://doi.org/10.1038/ncb3223 PMID: 26258631.

55. Drpic D, Almeida AC, Aguiar P, Renda F, Damas J, Lewin HA, et al. Chromosome Segregation Is Biased by Kinetochore Size. Curr Biol. 2018; 28(9):1344-56.e5. Epub 2018/05/01. https://doi.org/10. 1016/j.cub.2018.03.023 PMID: 29706521.

56. Jacquier NMA, Gilles LM, Pyott DE, Martinant JP, Rogowsky PM, Widiez T. Puzzling out plant reproduction by haploid induction for innovations in plant breeding. Nat Plants. 2020; 6(6):610-9. Epub 2020/ 06/10. https://doi.org/10.1038/s41477-020-0664-9 PMID: 32514145.

57. Maheshwari S, Tan EH, West A, Franklin FC, Comai L, Chan SW. Naturally occurring differences in CENH3 affect chromosome segregation in zygotic mitosis of hybrids. PLoS Genet. 2015; 11(1): e1004970. Epub 2015/01/27. https://doi.org/10.1371/journal.pgen.1004970 PMID: 25622028.

58. Sanei M, Pickering R, Kumke K, Nasuda S, Houben A. Loss of centromeric histone H3 (CENH3) from centromeres precedes uniparental chromosome elimination in interspecific barley hybrids. Proc Natl Acad Sci U S A. 2011; 108(33):E498-505. Epub 2011/07/13. https://doi.org/10.1073/pnas.1103190108 PMID: 21746892.

59. Comai L, Tan EH. Haploid Induction and Genome Instability. Trends Genet. 2019; 35(11):791-803. Epub 2019/08/20. https://doi.org/10.1016/j.tig.2019.07.005 PMID: 31421911.

60. Wang N, Gent JI, Dawe RK. Haploid induction by a maize cenh3 null mutant. Sci Adv. 2021; 7(4). Epub 2021/02/02. https://doi.org/10.1126/sciadv.abe2299 PMID: 33523932.

61. Marimuthu MPA, Maruthachalam R, Bondada R, Kuppu S, Tan EK, Britt A, et al. Biased removal and loading of centromeric histone $\mathrm{H} 3$ during reproduction underlies uniparental genome elimination. bioRxiv. 2021. https://doi.org/10.1101/2021.02.24.432754

62. Lv J, Yu K, Wei J, Gui H, Liu C, Liang D, et al. Generation of paternal haploids in wheat by genome editing of the centromeric histone CENH3. Nat Biotechnol. 2020; 38(12):1397-401. Epub 2020/11/11. https://doi.org/10.1038/s41587-020-0728-4 PMID: 33169035.

63. Fitzgerald MS, Riha K, Gao F, Ren S, McKnight TD, Shippen DE. Disruption of the telomerase catalytic subunit gene from Arabidopsis inactivates telomerase and leads to a slow loss of telomeric DNA. Proc Natl Acad Sci U S A. 1999; 96(26):14813-8. https://doi.org/10.1073/pnas.96.26.14813 PMID: 10611295

64. Alexander MP. Differential staining of aborted and nonaborted pollen. Stain Technology. 1969; 44 (3):117-22. https://doi.org/10.3109/10520296909063335 PMID: 4181665

65. Clarke JD. Cetyltrimethyl ammonium bromide (CTAB) DNA miniprep for plant DNA isolation. Cold Spring Harb Protoc. 2009; 2009(3):pdb prot5177. Epub 2010/02/12. https://doi.org/10.1101/pdb. prot5177 PMID: 20147112.

66. Brownfield L, Yi J, Jiang H, Minina EA, Twell D, Kohler C. Organelles maintain spindle position in plant meiosis. Nat Commun. 2015; 6:6492. https://doi.org/10.1038/ncomms7492 PMID: 25757555.

67. Talbert PB, Masuelli R, Tyagi AP, Comai L, Henikoff S. Centromeric localization and adaptive evolution of an Arabidopsis histone H3 variant. Plant Cell. 2002; 14(5):1053-66. https://doi.org/10.1105/tpc. 010425 PMID: 12034896.

68. Jasencakova Z, Meister A, Walter J, Turner BM, Schubert I. Histone H4 acetylation of euchromatin and heterochromatin is cell cycle dependent and correlated with replication rather than with transcription. Plant Cell. 2000; 12(11):2087-100. Epub 2000/11/23. https://doi.org/10.1105/tpc.12.11.2087 PMID: 11090211.

69. Derboven E, Ekker H, Kusenda B, Bulankova P, Riha K. Role of STN1 and DNA polymerase alpha in telomere stability and genome-wide replication in Arabidopsis. PLoS Genet. 2014; 10(10):e1004682. https://doi.org/10.1371/journal.pgen.1004682 PMID: 25299252. 
70. Valuchova S, Fulnecek J, Prokop Z, Stolt-Bergner P, Janouskova E, Hofr C, et al. Protection of Arabidopsis Blunt-Ended Telomeres Is Mediated by a Physical Association with the Ku Heterodimer. Plant Cell. 2017; 29(6):1533-45. https://doi.org/10.1105/tpc.17.00064 PMID: 28584163.

71. Livak KJ, Schmittgen TD. Analysis of relative gene expression data using real-time quantitative PCR and the 2- $\Delta \Delta$ CT method. Methods. 2001. https://doi.org/10.1006/meth.2001.1262 PMID: 11846609 